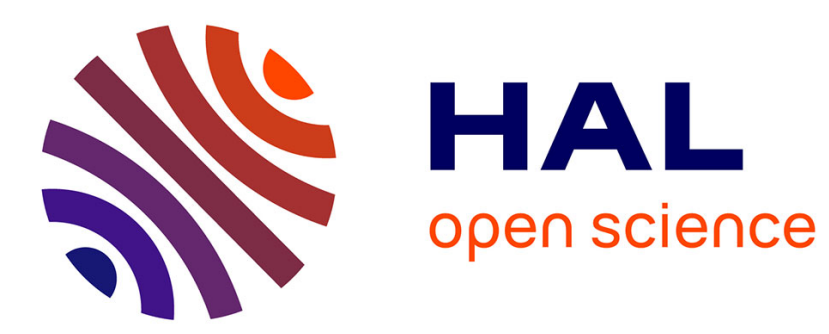

\title{
The effect of metapopulation dynamics on the survival and spread of a novel, conspicuous prey
}

Thomas J. Lee, Michael P. Speed

\section{To cite this version:}

Thomas J. Lee, Michael P. Speed. The effect of metapopulation dynamics on the survival and spread of a novel, conspicuous prey. Journal of Theoretical Biology, 2010, 267 (3), pp.319. 10.1016/j.jtbi.2010.08.027 . hal-00634000

\section{HAL Id: hal-00634000 \\ https://hal.science/hal-00634000}

Submitted on 20 Oct 2011

HAL is a multi-disciplinary open access archive for the deposit and dissemination of scientific research documents, whether they are published or not. The documents may come from teaching and research institutions in France or abroad, or from public or private research centers.
L'archive ouverte pluridisciplinaire HAL, est destinée au dépôt et à la diffusion de documents scientifiques de niveau recherche, publiés ou non, émanant des établissements d'enseignement et de recherche français ou étrangers, des laboratoires publics ou privés. 


\section{Author's Accepted Manuscript}

The effect of metapopulation dynamics on the survival and spread of a novel, conspicuous prey

Thomas J. Lee, Michael P. Speed

PII: S0022-5193(10)00450-9

DOI: doi:10.1016/j.jtbi.2010.08.027

Reference: YJTBI 6131

To appear in: $\quad$ Journal of Theoretical Biology

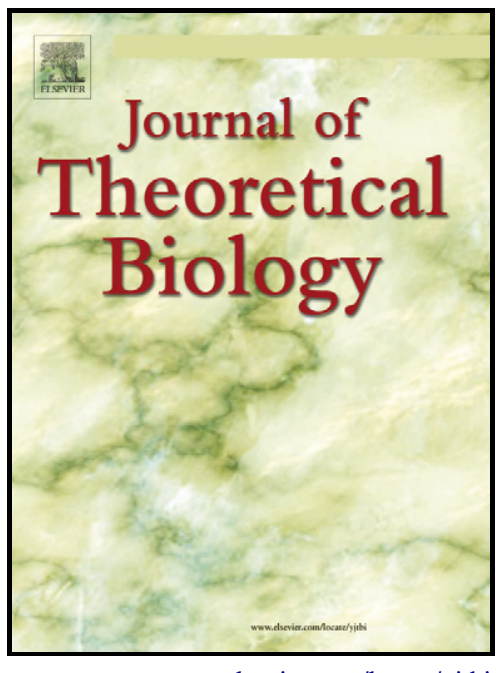

www.elsevier.com/locate/yjtbi

Received date: 14 December 2009

Revised date: $\quad 30$ July 2010

Accepted date: 24 August 2010

Cite this article as: Thomas J. Lee and Michael P. Speed, The effect of metapopulation dynamics on the survival and spread of a novel, conspicuous prey, Journal of Theoretical Biology, doi:10.1016/j.jtbi.2010.08.027

This is a PDF file of an unedited manuscript that has been accepted for publication. As a service to our customers we are providing this early version of the manuscript. The manuscript will undergo copyediting, typesetting, and review of the resulting galley proof before it is published in its final citable form. Please note that during the production process errors may be discovered which could affect the content, and all legal disclaimers that apply to the journal pertain. 
The effect of metapopulation dynamics on the survival and spread of a novel, conspicuous prey

Thomas J. Lee

Michael P. Speed

School of Biological Sciences

Biosciences Building

Crown Street

University of Liverpool

Liverpool L69 7ZB

Author to whom correspondence should be addressed: Thomas J. Lee (thomas.lee@liv.ac.uk)

Word count : 6593

Keywords : aposematism, crypsis, metapopulation, frequency dependant selection, neophobia, dietary conservatism, individual based modelling, ecological modelling.

\section{Abstract}

Page 1 of 39 
Animals that deploy chemical defences against predators often signal their unprofitability using bright colouration. This pairing of toxicity and conspicuous patterning is known as aposematism. Explaining the evolution and spread of aposematic traits in previously cryptic species has been the focus of much empirical and theoretical work over the last two decades. Existing research concerning the initial evolution of aposematism does not however properly consider that many aposematic species (such as members of the hymenoptera, the lepidoptera, and amphibia) are highly mobile. We argue in this paper that the evolution of aposematic displays is therefore often best understood within a metapopulation framework, hence in this paper we present the first explicit metapopulation model of the evolution of aposematism. Our most general finding is that migration tends to reduce the probability that an aposematic prey can increase from rarity and spread across a large population. Hence, the best case scenarios for the spread of aposematism required fixation of the aposematic form in one or more isolated sub-habitats prior to some event which subsequently enabled migration. We observed that changes in frequency of new aposematic forms within source habitats are likely to be nonmonotonic. First, aposematic prey tend to decline in frequency as they migrate outwards from the source habitat to neighbouring sink habitats, but subsequently they increase in relative abundance in the source, as the descendents of earlier migrants migrate back from newly converted sub-populations. This pattern of initial loss and subsequent gain between new source and neighbouring sink habitats is then repeated as the aposematic form spreads via a moving cline.

\section{Introduction}

Page 2 of 39 
Many prey protect themselves from predation by the possession of a secondary defence, often some form of toxin. To deter predation toxicity is often accompanied by bright colouration and this pairing of defensive traits is known as aposematism. Aposematism is notably common throughout the animal kingdom (Cott 1940; Edmunds 1974; Poulton 1890), and it is now well established that aposematic displays provoke a number of responses from predators that increases the probability that a prey survives encounters (such as wariness, and accelerated learning; see review in Ruxton 2004).

Though the proximate function of aposematic displays is well understood, the evolutionary processes that bring them into existence are less clear. It is a widely held assumption that aposematic warning displays initially evolved in species already adopting some form of secondary defence combined with crypsis (Harvey et al. 1982; Leimar et al. 1986; Yachi and Higashi 1998). In such populations, a novel, aposematic mutant would face two major evolutionary hurdles. First, the novel conspicuous prey would attract the attention of naive predators making it likely that it is attacked and killed.

Second, even if the novel conspicuous prey survived and reproduced, with low absolute numbers, all individuals may be consumed before predators learn that the prey are unprofitable. Theory therefore predicts a critical abundance level above which aposematic displays are sufficiently common to be selectively favoured and it is generally assumed that this level is much higher than the initial abundance of new aposematic mutants (Mallet and Singer 1987; Puurtinen and Kaitala 2006; Servedio 2000; Speed and Ruxton 2007, 2005).

There are a growing number of explanations which seek to resolve this evolutionary puzzle (review in Ruxton et al. 2004). A recent evolutionary model presented by Lee et al. (2010) for example, showed that predator wariness of phenotypic novelty in prey (sometimes known as dietary conservatism) may have played an important role in the initial evolution of aposematic warning displays, in contrast to the somewhat sceptical views previously presented in the literature (Mallet Page 3 of 39 
and Singer 1987; Speed 2001). Lee et al used stochastic evolutionary modelling of prey within a single habitat and found that dynamically stable dimorphisms between aposematic and cryptic prey could be sustained over long periods of time in the presence of a predator showing even quite modest levels of wariness.

A striking feature of existing theoretical models of aposematism, is that researchers have considered only single predator-prey habitats despite strong evidence that many aposematic species reside in patches and generally conform to a metapopulation structure. For example the red-spotted newt (Notophthalmus viridescens), believed to be aposematic, is a resident in the fragmented pondscape of eastern America and its red (eft) stage is the vehicle for inter-habitat migration (Gill 1978; Shure et al. 1989). Indeed, the majority of amphibian species are thought to adhere to some level of metapopulation structure and dynamics (Marsh and Trenham 2001) with numerous examples deploying aposematic colouration as an antipredator defence, most pertinently the Dendrobatidae frogs (Saporito et al. 2007). Similarly, many aposematic Lepidoptera adhere to general metapopulation structure, one example being the six-spot burnet moth (Zygaena filipendulae),(Menendez et al. 2002).

Despite the omission of spatial structure from formal models, one of the earliest theoretical treatments of the evolution of aposematism by Mallet \& Singer (1987) pre-supposes some level of mobility in prey and therefore invites a metapopulation approach. Mallet \& Singer (1987) argued that if aposematism evolved within a single habitat the trait could spread outwards destabilising crypsis in neighbouring localities, causing a moving cline of prey colouration which would lead to the entire prey population switching from crypsis to aposematism. A recent paper by Endler and Rojas (2009) examines the effect of prey dispersion across varied predator (receiver) territories on the viability of frequency dependant traits such as aposematic warning displays with some interesting Page 4 of 39 
insights. To date however, there have to our knowledge, been no specific metapopulation treatments of aposematic evolution, and so the major aim of our present paper is to create a metapopulation framework and evaluate how and whether aposematism might evolve and spread over a large, heterogeneous environment. Our population structure-approach is similar to that taken by Sherratt (2006), but where Sherratt focused on explaining diversity in mimicry systems, we are concerned with examining how the dynamics of prey evolution within and between habitats interact to prevent or facilitate a change in prey defence.

In this paper we build on the simple one-habitat model of predation described in Lee et al. (2010) and in the first section we compare aposematic evolution in a self-contained single population (summarised from their paper) with evolution in a metapopulation structure. In the second section of the paper, we consider in detail the evolutionary dynamics in the case suggested by Mallet $\&$ Singer (1987), in which aposematism has evolved in one or more isolated sub-habitats which becomes susceptible to the influences of prey migration if an isolating barrier is removed. We show that metapopulation structure and the inter-habitat movement of prey make it more difficult for aposematism to evolve from rarity. Where we assume that aposematism has evolved in isolated source sub-habitats we find that the optimal conditions for its spread across the entire metapopulation are where levels of migration are low, where the number of clustered source habitats is high and finally when a single predators foraging area matches the area inhabited by a single sub-population.

\section{Model Introduction}

We consider a habitat with avian predators that are strongly territorial in their foraging area (Smith 1974; Snow 1966), and hence each habitat within our metapopulation contains a single predator who forages within that habitat for its lifetime (However in later models we relax this structural rigidity Page 5 of 39 
and allow predators to move between habitats both within and between prey seasons). Our metapopulation model consists of a number of sub-habitats represented in a regular square lattice. Prey are allowed to move between sub-habitats, with a given number allowed to migrate to each of the 8 surrounding sub habitats at the end of each season (Sherratt 2006). Predators, are assumed to die after a defined number of prey seasons after which they are replaced by another predator whose prey choice decisions may be different from its predecessor. We are not modelling the initial evolution of aposematism, rather the survival of conspicuous mutants in a world in which predators have already evolved innate predispositions to avoid novel prey with bright aposematic colouration for some number of exposures (see Ruxton et al. 2004 for a review). In field studies with wild birds, the level of wariness was found to vary considerably between individuals (see table 2 from Marples et al. 1998) and as such we assign wariness levels randomly drawn from this dataset. In addition, it is well known that aposematic signals may accelerate avoidance learning rates in predators, and in our simulations we evaluate the effects of a wide range of learning rates. We first describe a single habitat, and then the metapopulation structure.

\section{Description of a single habitat}

Within each cell of the metapopulation we modelled a finitely sized hypothetical habitat in which one predator and a number of prey $(\mathrm{N})$ reside. Within the prey population two distinct prey types exist, cryptic $\left(c_{c}\right.$, of number $\left.N_{c}\right)$ and aposematic $\left(c_{a}\right.$, of number $N_{a}$, where $\left.N_{c}+N_{a}=400\right)$. We assume that both prey types are equally distasteful to the predator and we assume that at the start of the simulations prey are cryptic with the exception of rare aposematic mutants that can emerge at the start of a prey generation. Each prey type is assigned a value for conspicuousness, $\left(c_{a}\right)$ for the aposematic prey type and $\left(c_{c}\right)$ for the cryptic type which represents the probability of detection by the predator, given that a predator and prey are within some minimum level of proximity. The two prey Page 6 of 39 
types are also each assigned an avoidance learning rate, $\left(\alpha_{a}\right)$ for the aposematic prey type and $\left(\alpha_{c}\right)$ for the cryptic prey, used to determine the rate at which the predator learns to avoid each prey type as a result of their distastefulness. The model iterates in prey generations (seasons) which have a finite time limit $(T)$.

During each season, the predator moves through the habitat at random until it comes within striking distance of one individual prey; we assume time taken for this stage is $1 /$ Total number of living prey in that habitat (in arbitrary time units). The chance of the predator detecting a prey individual is dependent on the prey's conspicuousness value $\left(c_{a}, c_{c}\right)$ which is compared against a randomly generated number between 0 and 1 inclusive. If for example, we set $c_{c}=0.01$ and $c_{a}=0.02$ then the aposematic prey has twice the chance of being detected over its cryptic counterpart (as is the case in all our models). If the prey in striking distance is not detected, the predator moves randomly through the habitat and repeats this process until a victim is finally selected. Once the victim has been selected, the predator then has the option of rejecting it without attacking, based on a rejection probability $(R)$. This is dependent on two predator behaviours.

Predator wariness of bright, novel prey

The predator has a wariness "memory" (termed $D C_{\text {num }}$ ) for which a value is assigned e.g. 30. In this case the first 30 aposematic prey encountered by the predator are rejected (chance of rejection $R_{a}=1$ ). When sufficient aposematic prey have been encountered by the predator i.e. when number encountered $=\mathrm{DC}_{\text {num }}+1$, wariness is absent and the predator now behaves like an inexperienced animal (so that rejection probability $R_{a}=0$, see equation 1a); subsequent learning can increase the value of $R_{a}$. More complex methods of modelling wariness have been shown to make no material 
difference to the evolutionary outcomes (Lee et al. 2010). We based all of our predator wariness values $\left(D C_{\text {num }}\right)$ on the field data for dietary conservatism in wild blackbirds (Marples, 1998).

\section{Avoidance Learning}

Here, the predator can increase the chance of rejection of a prey type based on previous experiences ( $R_{a}$ for aposematic prey, $R_{c}$ for cryptic prey). The probability of rejection of a specific prey type increases the more often it has been attacked; for simplicity we use a negative exponential term to describe this. For aposematic prey:

$$
R_{a}=1-e^{-\alpha_{a} \cdot L_{a}}
$$

And for cryptic prey:

$$
R_{c}=1-e^{-\alpha_{c} \cdot L_{c}}
$$

Where $L_{a}$ and $L_{c}$ refer to the number of attacks that a predator has had with an aposematic or a cryptic prey respectively. When predators are inexperienced then $L_{a}$ and $L_{c}$ equal zero and probability of attack given detection is 1 (In our Appendix, Figure A1 we display the avoidance learning curves for a range of $\alpha$ values). If rejection does occur we assume the time taken for this is 0.5 arbitrary time units. If the victim is not rejected by the predator then the victim is killed and the population updated at a time cost of 1 arbitrary time unit. The predation process continues until the current time measure $(t)$ eventually reaches the time limit for the generation $(\mathrm{T})$. The prey are then repopulated stochastically and asexually whereby each new individual in the population is assigned a randomly generated number between 0 and 1 which is compared to the ratio of prey morphs 
surviving the previous season. With an asexual population random drift is caused by the stochastic nature of predator behaviour and the stochastic repopulation of prey between generations.

\section{A metapopulation extension to the single habitat model}

We modelled a 50 x 50 grid of sub-habitats arranged in a regular square lattice structure, with each sub habitat containing a prey population and predator as described above. Initially, we allocate each sub-habitat a predator with a $\mathrm{DC}_{\text {num }}$ sampled randomly from the predator pool (Table 2). The predators are assumed to be naive at the start of the simulation i.e. all encounter memories are 0 .

In all metapopulation models we consider a mutation rate of $10^{-5}$. The initial number of aposematic prey is then calculated by multiplying this mutation rate by the total number of prey across all subhabitats $\left(10^{-5} \times(400 \times 50 \times 50)=10\right)$ hence each prey generation we spawn 10 new aposematic mutants $\left(c_{a}=0.02\right)$ randomly across the entire metapopulation. We omit the effects of back-migration in the cryptic form due to all models starting with overwhelming numbers of cryptic prey. Pilot runs were performed to determine the chance that a cryptic morph could invade from rarity (with a mutation rate of $10^{-5}$ ). In all cases the cryptic morph rapidly became extinct (Puurtinen and Kaitala 2006).

Migration

Page 9 of 39 
Once the starting population and predator locations have been established, the predation process for each sub-habitat is executed sequentially. When complete, the starting populations for the next generation are established (as per the single-habitat model description above). Within each subhabitat, a proportion of the new prey population are then randomly selected for migration $\left(8 \mathrm{x} N_{\text {mig }}\right)$ which are then further randomly divided into 8 subgroups of size $\left(N_{m i g}\right)$ which represent the migratory population destined for each of the surrounding 8 sub-habitats. The model iterates until a defined number of prey generations $\left(m i g_{g e n}\right)$. Each sub-habitat will consequently gain and lose $\left(8 \mathrm{x} N_{\text {mig }}\right)$ prey individuals each generation. At the borders of the metapopulation, we assume a continuous torus arrangement so that no migratory boundaries exist (Sherratt 2006)

Predator Lifespan \& Replacement

We allow predators to outlive their prey by a definable number of generations using a parameter called $\left(\right.$ pred $\left._{\mathrm{gen}}\right)$ which defines the age at which a predator is replaced. In models where predators live for greater than 1 prey generation, at the beginning of the simulation we assign predators a random age $\left(0:\right.$ pred $_{\text {gen }}-1$ inclusive $)$ which is incremented each prey generation. When the predator's age reaches the critical value ( pred $_{\text {gen }}$ ), the predator is replaced. We assume that when replacement occurs, a new naive predator migrates into each sub-habitat with a $D C_{n u m}$ drawn randomly from the pool of predator DC values (Table 2).

\section{Detailed scenarios and results}

Part 1: Single Habitat vs. Metapopulation Models

Page 10 of 39 
In a recently published paper, Lee et al. (2010) provided a set of predictions for the conditions under which aposematism might have evolved in single habitats. We re-ran these simulations, but now applied the same parameters to the metapopulation model. The resulting dataset is large and hence we present a table comparing the results of single and meta-population models (Table 3 ) here in the main text, but provide a detailed set of results in the Appendix. As with Lee et al. we considered the critical value of avoidance learning rate about aposematic displays as an index of how easily aposematism could evolve. If conditions in the model were favourable for aposematism to evolve from rarity and spread, then $\alpha_{\mathrm{a}}$ need not be much greater than $\alpha_{\mathrm{c}}$ to enable this, since aposematism would not need a strong selective benefit from biased avoidance learning rates. In contrast where conditions were unfavourable for the evolution and spread of aposematism, it is likely that the minimum value of $\alpha_{a}$ would need to be much greater than $\alpha_{c}$ to compensate and improve selection for the aposematic prey to enable them to evolve and spread. In the metapopulation models presented in this section we allow migration to occur at a fixed rate of $\left(\mathrm{N}_{\mathrm{mig}}=10\right)$ equating to $20 \%$ of the prey population and adopt the standard set of parameters (Table 1).

When we simulated predators that have no initial wariness in handling bright prey, both single and meta-population models yielded the same result, in that the aposematic morph became extinct. When predator wariness is added to the model, aposematism evolved in both the single and metapopulation models, however metapopulation structure and migration tended to prevent the conversion of crypsis to aposematic colouration. For our tested level of migration $(20 \%$ of the prey population moving from each habitat, each season), aposematism would only evolve to reach fixation with a higher learning rate $\left(\alpha_{\mathrm{a}}>=0.18\right)$ than in the single habitat model $\left(\alpha_{\mathrm{a}}=0.08\right)$. However, where migration prevented fixation, it could lead to stable dimorphisms in the prey populations (see Table 3 and Figure 1) which could not be demonstrated in single habitat models. Where fixation of the aposematic morph occurred in our initial metapopulation models, the spread of the aposematic Page 11 of 39 
prey propagated outwards from a single source habitat in all trials (example in Figure 2). Finally, when predators live for 5 prey generations and with levels of predator wariness selected randomly from the dataset (table 2), the inter-habitat migration of prey (at the level of $20 \%, \mathrm{~N}_{\mathrm{mig}}=10$ ) acts to prevent any increase in abundance of the aposematic morph even when we assume virtually instantaneous avoidance learning $\left(\alpha_{\mathrm{a}}=0.99\right)$.

\section{Model development: migration from source habitats}

We next consider that aposematism may have initially evolved within one or more habitats that are isolated from the rest of the metapopulation, but at some point, prey migration becomes possible (see Mallet \& Singer, 1987). In model terms, at the start of the simulation we simply assign all individuals of these source habitats to be aposematic $\left(c_{a}=0.02\right)$ and begin migration from generation $1\left(\right.$ miggen $\left._{\text {gen }}\right)$. Initial pilot runs showed that where we consider that aposematism has evolved in just 1 single sub-habitat, the critical avoidance learning rate required for viable out-migration and spread was very high ( $\alpha_{\mathrm{a}}=0.9$, almost single trial learning) with our migration rate of $\mathrm{N}_{\text {mig }}=10$. Further pilot tests revealed that adding four geographically separate source habitats made no difference to the critical avoidance learning rate required for aposematism to spread, however clumping of several source habitats greatly increased the probability of successful export of the aposematic form across the whole habitat.

We next adopted the more favourable case where we assume aposematism has evolved in a localised clump of four source habitats and we evaluated the circumstances under which aposematism could spread into the rest of the metapopulation from this starting point. All parameters are as per the standard model $\left(\right.$ generations $=2000, \mathrm{~T}=100, \mathrm{c}_{\mathrm{a}}=0.02, \mathrm{c}_{\mathrm{c}}=0.01, \alpha_{\mathrm{c}}=0.04$, mutation rate $=10^{-5}$, Page 12 of 39 
$\mathrm{N}_{\text {mig }}=10$ ). We consider the case in which predators live for 5 prey generations ( $\operatorname{pred}_{\mathrm{gen}}=5$ ). A series of tests were performed with increasing values of avoidance learning rate for aposematic prey $\left(\alpha_{a}\right.$ $=0.04-0.99$ ) to determine if fixation of the aposematic morph was possible from these starting points.

In previous metapopulation models where aposematic prey arise randomly across the metapopulation and where $\mathrm{N}_{\mathrm{mig}}=10$, fixation of the aposematic morph was never demonstrated in models where predators outlive their prey (Table 3). Where we assume that migration from a group of 4 clumped source habitats occurs at a rate of $\mathrm{N}_{\mathrm{mig}}=10$, we now demonstrate fixation of the aposematic morph across the entire metapopulation when $\alpha_{a}>=0.55$ (Figures $3 \& 4$ ).

\section{Variation in Migration Rate}

Next, we considered the effects of migration rate on the viability of the aposematic morph. We adopted the same parameters as the previous source habitat model in which we assume 4 clumped sub-habitats begin at aposeme fixation and the predators live for 5 prey generations $\left(\right.$ pred $\left._{\text {gen }}=5\right)$.

However, we now re-tested the model with varied levels of migration $\left(N_{m i g}=2, N_{m i g}=5\right.$ and $\left.N_{m i g}=20\right)$. For each, we tested a series of avoidance learning rates for aposematic prey $\left(\alpha_{a}=0.04-0.99\right)$ to determine the critical level required for aposeme fixation across the entire metapopulation.

Where migration rate was highest $\left(N_{m i g}=20\right)$ the aposematic morph did not increase in abundance in any of the trials $\left(\alpha_{a}=0.04-0.99\right)$ and rapidly became extinct. In contrast when migration was reduced to $N_{m i} g=5$ there was dramatically improved survival for the aposematic morph (with fixation occurring where $\alpha_{a}>=0.38$. Finally when we reduced migration rates further to $N_{m i g}=2$ we obtained

Page 13 of 39 
a further reduction in the critical avoidance learning rate required for total aposeme fixation across the entire metapopulation $\left(\alpha_{\mathrm{a}}=0.18\right)$.

\section{The dynamics of migration}

\section{Migration-selection balance in a habitat without backward migration}

In order to better understand the dynamic effects of migration on the spread of the aposematic form, we modelled a series of simple scenarios, looking at the effects of selection and movement of prey on the net change in frequencies of prey forms. We start with a very simple scenario designed to examine the relationship between loss of aposematic forms through outward migration and gain from intergenerational selection. For simplicity we have not included backward migration (we deal with this later). We modelled the source habitat over 1 prey generation in order to determine whether the increase in abundance due to selection (i.e. the average increase in abundance of aposematic prey over 1 generation) was greater than the average removal of aposematic prey via out-migration for the same interval (and we subsequently extend the analysis to models that consider more habitats). We modelled a series of starting abundances for aposematic prey (20-380 aposematic prey in increments of 20) and ran the model for 10,000 repetitions to give a robust estimate of the average gain in abundance of aposematic forms due to selection and the average loss from migration. The models were tested with the following parameters (generations $=1, \mathrm{~N}_{c}=400-\mathrm{N}_{\mathrm{a}}, N_{a}=20-380, T=100, \quad c_{a}=0.02$, $c_{c}=0.01, \alpha_{c}=0.04, \alpha_{a}=0.35$ pred $_{\text {gen }}=5, D C_{\text {num }}=$ random $($ Table2) $)$. Each model was tested for three migration rates, $\mathrm{N}_{\mathrm{mig}}=2, \mathrm{~N}_{\mathrm{mig}}=5, \mathrm{~N}_{\mathrm{mig}}=10$.

Page 14 of 39 
When migration rates were set to $\mathrm{N}_{\text {mig }}=5, \mathrm{~N}_{\text {mig }}=10$, the rate of change from selection was too weak to recoup the rapid loss in abundance due to outmigration. In contrast, where $\left(\mathrm{N}_{\mathrm{mig}}=2\right.$, Figure 5) we observe that the number of aposematic prey gained by selection can be higher than that lost to outmigration, but only when they are at some intermediate frequency within the habitat (circa 110-210 individuals). This result is explained by the fact that selection is weak toward the extremes of frequency distributions, so that at high or low frequencies of aposematic prey, the numbers replenished by natural selection are less than those removed by migration. The point on the $\mathrm{X}$ axis of 110 prey, ( $\mathrm{A}$ in the graph) is a bifurcation point, below which prey move toward extinction and above which they increase in frequency to an equilibrium value at cerca 210 aposematic forms (B in the graph). At this point outward migration and selection are in balance and the equilibrium is stable (values higher than this lead to reductions in aposematic numbers back to equilibrium, values lower than this lead to increases in their numbers up to equilibrium). In itself, however, this scenario is not sufficient to explain how the aposematic form can take over the entire range of the prey in a metapopulation, since it predicts a stable aposematic frequency somewhat less than fixation.

\section{Migration-selection balance in a more realistic case}

We next expanded our considerations to include both outmigration and inward migration from neighbouring habitats. For simplicity we consider a 6x6 square metapopulation grid with the centre sub-habitat starting at aposeme fixation $\left(\mathrm{N}_{\mathrm{a}}=400\right)$, all individuals in the surrounding habitats were assigned to be cryptic. As with our larger metapopulation model, we again assume a torus effect at the edges of the lattice. The model was tested adopting the following parameters (generations $=100$, $\mathrm{T}=100, \mathrm{c}_{\mathrm{a}}=0.02, \mathrm{c}_{\mathrm{c}}=0.01, \alpha_{\mathrm{c}}=0.04, \alpha_{\mathrm{a}}=0.38, \operatorname{pred}_{\text {gen }}=5, \mathrm{DC}_{\mathrm{num}}=\operatorname{random}($ Table 2$\left.), \mathrm{N}_{\mathrm{mig}}=5\right)$ and the Page 15 of 39 
abundance of aposematic prey in the source habitat was recorded for each generation as well as the number of aposematic prey lost to outmigration and the number of aposematic prey gained by inmigration (Figure 6a).

The most important result is that changes in the frequency of the aposematic form in the source habitat are not monotonic. First, this morph declines in frequency due to outmigration. Selection favouring aposematism over crypsis is weak close to fixation, and so initially more prey leave the source via migration than return via selection (as in the simpler scenario above). Unlike the simpler scenario though, the aposematic form subsequently increases in frequency toward fixation. This is explained by the descendents of the original aposematic emigrants returning via inward migration from neighbouring habitats that increasingly convert to aposematism. Indeed, inward and outward migration of aposematic forms reach equilibrium, around generation 45, and subsequently natural selection favouring aposematism causes this prey form to increase to fixation (Figure 6a). This analysis of optimal migration creates a specific simple rule which should promote outward migration from a source habitat:

$\Delta N_{s}+N_{\text {in }}>=N_{\text {out }}$

Where $\Delta \mathrm{N}_{\mathrm{s}}$ is the change in aposeme number due to selection in a given season, $\mathrm{N}_{\text {in }}$ represents the number of aposematic prey gained in the source habitat from back migration over 1 season and $\mathrm{N}_{\text {out }}$ represents the number of aposematic prey lost from the source habitat through out-migration over 1 season. Although our simplistic migration rule deals only with frequency dependent competition between competing prey morphs it draws similarity to habitat occupancy and colonization rules presented throughout the metapopulation literature (Hanski 1999).

Page 16 of 39 
These simulations help to explain why clustering of source habitats is so important for the evolution of aposematism across a metapopulation. Spatial proximity of "aposematic habitats" allows both inward and outward migration of aposematic forms. Clustering of source habitats should therefore reduce the net loss from source habitats due to in-migration from neighbouring or central source habitats, thus increasing $\mathrm{N}_{\mathrm{in}}$.

One prediction that follows is that habitats at the centre of a cluster should show less change than habitats at the fringes. To examine this prediction we next considered a clump of 9 source habitats arranged in a $3 \times 3$ grid, again placed at the centre of our $6 \times 6$ test metapopulation. Individuals in the surrounding sub-habitats were all cryptic. All other model parameters were as per the previous in/out-migration model (generations $=100, \mathrm{~T}=100, \mathrm{c}_{\mathrm{a}}=0.02, \mathrm{c}_{\mathrm{c}}=0.01, \alpha_{\mathrm{c}}=0.04, \alpha_{\mathrm{a}}=0.38$, pred $_{\text {gen }}=5$, $\mathrm{DC}_{\text {num }}=$ random $\left(\right.$ Table2), $\mathrm{N}_{\mathrm{mig}}=5$ ). We tracked frequency of aposematic forms in one of the border source habitats which fringes upon the cryptic populations, and similarly for the centre source habitat which is surrounded only by other source habitats (Figure 6b). For comparison we also plot the tracked frequency of aposematic prey from the solitary source habitat model (Figure 6a).

As predicted, the overall net loss of aposematic prey was much lower for both the border and central source habitats in the $3 \times 3$ cluster than in single source habitat. It is evident therefore, that clustering of source habitats can provide extra protection from swamping of the source habitats, preventing the numbers of aposematic prey from dropping to levels where selection may become negative and extinction could occur (Puurtinen and Kaitala 2006). The results also show that the overall net loss of aposematic prey from the centre of the $3 \times 3$ cluster of source habitats is much less than in the border habitats (Figure 6b).

Page 17 of 39 
In light of this finding we applied the $3 \times 3$ cluster of source habitats to our large 2500 habitat metapopulation framework to determine if larger cluster size could lower the critical avoidance learning rate for aposematic prey required for fixation throughout the entire metapopulation. We adopted the same parameters as our original models (generations $=2000, \mathrm{~T}=100, \mathrm{c}_{\mathrm{a}}=0.02, \mathrm{c}_{\mathrm{c}}=0.01$, $\alpha_{c}=0.04, \operatorname{pred}_{\text {gen }}=5, \operatorname{mig}_{g e n}=1$, mutationrate $=10^{-5}$ ) with our optimal migration rate of $\mathrm{N}_{\mathrm{mig}}=2 . \mathrm{We}$ found that where we assume 9 clumped source habitats begin at aposeme fixation (arranged in a 3x3 clump), the critical avoidance learning rate for aposematic prey required for total fixation was reduced to $\left(\alpha_{a}=0.1\right)$, considerably lower than the previous model in which we consider just 4 clustered source habitats and a migration rate of $\mathrm{N}_{\mathrm{mig}}=2$ where the critical level was found to be $\left(\alpha_{a}\right.$ $=0.18)$.

\section{Predator Movement}

In our next presentation of the model, we consider the effects of predator movement on the survival and spread of the aposematic morph. Our previous models consider a scenario in which a predator's foraging area exactly matches the area inhabited by a single sub-population. Here we relax this assumption and consider the effects of varying predator territory (see Endler and Rojas 2009). We consider two extensions: the first ("Increased Local Predator Foraging Area"), in which each subpopulation suffers predation from several localized predators which are temporally spaced. In the second extension ("Random Predator Dispersal"), we consider a case in which predators are highly mobile and can move freely and randomly between sub-habitats, each prey season.

Increased Local Predator Foraging Area

Page 18 of 39 
In this model we allow for localized predator movement within the duration of a prey season. We again assume territoriality in that we only allow one predator to forage in any given time window. This is accomplished by dividing the time limit for a prey season ( $\mathrm{T}=100$ in all models) by the number of predators assumed to enter the habitat during the prey season (which in the case of all tested models was 4) hence each predator forages in the target habitat for 25 arbitrary time units. The predators selected to forage in the target habitat consist of the predator assigned to the habitat at the beginning of the prey season along with 3 others selected randomly from the neighbouring 8 habitats.

The model was tested initially in a 10x10 lattice model in which the centre 4 sub-habitats begin at aposeme fixation (although we showed previously that larger numbers of grouped source habitats make aposematism more likely to spread, we consider this to be a more realistic case). The parameters were as follows (generations $=100, \mathrm{~T}=100, \mathrm{c}_{\mathrm{a}}=0.02, \mathrm{c}_{\mathrm{c}}=0.01, \alpha_{\mathrm{c}}=0.04, \alpha_{\mathrm{a}}=0.04-0.99$, $\operatorname{pred}_{\text {gen }}=5, \mathrm{DC}_{\text {num }}=$ random $\left(\right.$ Table2), $\left.\mathrm{N}_{\mathrm{mig}}=5\right)$. The model was tested as per previous simulations with a range of avoidance learning rates for aposematic prey to determine the critical level required for aposeme fixation. We found that localized movement of predators and overlap between territories acted to prevent the spread of the aposematic morph, requiring an avoidance learning rate of value of $\alpha_{\mathrm{a}}=0.8$ (as opposed to $\alpha_{\mathrm{a}}=0.18$ with fixed predators). This result was subsequently verified in the 50x50 lattice model, requiring an avoidance learning rate of $\alpha_{a}=0.85$ for aposeme fixation across the metapopulation.

Random Predator Dispersal

Page 19 of 39 
In this model we consider that each prey generation, predators are allowed to roam globally and settle in a new sub-habitat each prey generation. Computationally this is achieved by randomly shuffling the matrices containing the predator $\mathrm{DC}_{\text {num }}$ values as well as the corresponding memory counter data from previous experiences so that each predator carries it relevant counter data with it to its new destination. Again the model was tested with the following parameters (generations=100, $\mathrm{T}=100, \mathrm{c}_{\mathrm{a}}=0.02, \mathrm{c}_{\mathrm{c}}=0.01, \alpha_{\mathrm{c}}=0.04, \alpha_{\mathrm{a}}=0.04-0.99, \operatorname{pred}_{\mathrm{gen}}=5, \mathrm{DC}_{\mathrm{num}}=$ random $($ Table2 $\left.), \mathrm{N}_{\mathrm{mig}}=5\right)$, initially in a 10x10 lattice model. We found that when predators were allowed to globally disperse between prey generations, the critical avoidance learning rate required for the aposematic prey to take fixation was $\alpha_{a}=0.35$ (compared to 0.18 for the fixed predator model; this is valid for both the $10 \times 10$ and 50x50 lattice models). We then re-ran the 50x50 lattice model with a migration rate of $\mathrm{N}_{\text {mig }}=50$, in which case we have total migration and dispersal of prey as well as predators, similar to the single habitat, changing predator model described by Lee et al, 2010. We found that the critical avoidance learning rate required for aposeme fixation across the metapopulation was $\alpha_{a}=0.8$, similarly high compared with the required learning rate found for a single habitat of $\alpha_{a}=0.99$ (Lee et al, 2010).

\section{Predator Free Space}

In the final presentation of our model we test the effect of reducing the overall number of predators present in the metapopulation. For brevity we consider only one treatment and reduce the number of predators across the metapopulation by half. This was achieved by adding a further 13 null predators $\left(\right.$ denoted by $\mathrm{DC}_{\text {num }}=0$ ) to the pool of predator values (see table 2 ), when a habitat receives a null

Page 20 of 39 
predator, the predation process is skipped and stochastic re-population proceeds. In keeping with the chronology of the study, we applied this addition to the aforementioned random predator dispersal model to determine the effect on the critical learning rate required for aposeme fixation. We did however increase the duration of the model to consider 10,000 prey generations to determine whether drift might allow the aposematic morph to increase in abundance in the absence of predation (pilot simulations showed that drift alone, in the absence of predation can account for the fixation of the aposematic morph across the metapopulation and in all 100 repetitions, this occured within 10,000 generations hence our decision to adopt this value). A series of avoidance learning rates for aposematic prey were tested $\left(\alpha_{a}=0.01-0.99\right)$. We found that when we reduce the number of predators by half, the critical avoidance learning rate required for fixation of the aposematic morph was raised to $\alpha_{\mathrm{a}}=0.7$ (in both the $10 \times 10$ lattice model) and $\alpha_{\mathrm{a}}=0.75$ (in the 50x50 lattice model).

\section{Discussion}

Previous theoretical approaches to modelling the evolution of aposematic warning displays neglect the effects that population structure may have on the first stages of aposematic evolution (Puurtinen and Kaitala 2006; Servedio 2000; Speed 2001; Thomas et al. 2004; Thomas et al. 2003; Yachi and Higashi 1998). In this paper we present the first theoretical metapopulation model of the evolution of aposematic warning displays from a receiver bias perspective, gaining insight into the process by which a novel conspicuous mutant may survive and spread throughout spatially distributed populations. Metapopulation theory encompasses a wide range of conceptual schemas (Hanski 1998). Our model adopts a spatially implicit discrete lattice approach which provides a robust framework on which to test the evolutionary effects of spatial structure while providing a reasonable approximation

Page 21 of 39 
of real-life habitat patch structure. This approach is commonly used when modelling theoretical population dynamics (Hanski 1998; Hanski 1999; Sherratt 2006) and adheres closely to traditional metapopulation theory (Hanski 1999; Levins 1969). In the discussion we consider the main features of the model and how these parameters effect the survival of the novel aposematic prey.

Perhaps the most important and general finding of our models is that, other things being equal, the presence of migration between sub-habitats tends to decrease the likelihood that aposematism will persist and spread from rarity. The reason for this result lies in the fact that there is a critical abundance below which an aposematic prey will not be favoured by selection (Puurtinen and Kaitala 2006). When aposematic prey are too rare, predators are ignorant of the fact that they are unprofitable and they tend to be attacked at high rates because of their unfamiliarity and conspicuousness. It is easy to see why migration is problematic for the aposematic form. If we consider a novel aposematic mutant that arises within cryptic population in a single habitat, and that it subsequently increases in frequency because of for example random drift or predator wariness. In the absence of migration the aposematic prey may become sufficiently numerous so that it becomes favoured by selection. But with outward migration to neighbouring habitats its numbers will be diminished in the source habitat to the point that selection acts against it and hence it rapidly becomes extinct. Therefore, in our simple metapopulation model, aposematism is typically much less likely to evolve than it would in a single habitat system. Since many prey populations exhibit nontrivial levels of migration, this appears to be an important conclusion. It has recently been argued that aposematism is rare relative to cryptic colouration across many animal taxa. We suggest that prey migration may be one of the most important ecological barriers to the establishment of this defensive trait. (Przeczek et al. 2008).

\section{Importance of localisation}

Page 22 of 39 
With strong biases in predator behaviour favouring aposematic morphs over cryptic forms, fixation within one habitat could be sufficient to explain the successful export of aposematism across the whole population (see Table 1). We could, however, explain the spread of an aposematic trait most plausibly if we assumed that it initially rises to high frequencies within more than one habitat, especially if these habitats are clustered closely together prior to outmigration. This localised increase in abundance may be plausible in favourable conditions such as habitats which are temporarily predator-free combined with stochastic drift effects (Lee et al. in press; Mallet and Singer 1987) or where resident predators show extreme wariness of novel coloured prey (Lee et al. in press; Marples et al. 2005; Thomas et al. 2004; Thomas et al. 2003). The benefits from the clustering of source habitats for the spread of the aposematic form comes from reducing the overall net loss of aposematic prey from any given habitat within the source cluster, thus ensuring that numbers never drop below or near to the bifurcation point (point A, Figure 5) where there is a potential risk of extinction. Considering our $3 \times 3$ cluster of source habitats, a habitat in this cluster bordering the cryptic populations will suffer a lower net loss of aposematic prey in comparison to a single source habitat simply due to the inmigration of aposematic prey from neighbouring "aposematic habitats". Similarly the habitat at the centre of the $3 \times 3$ source habitat clump will undergo an even lower net loss as it is surrounded only by "aposematic habitats" (Figure 6b).

\section{Predator Movement}

Our models show that localized predator movement within a prey season, effectively modelling increased predator foraging area, acts to inhibit the survival and spread of the aposematic form. This result pertains because predators, although exhibiting dietary conservatism, do not consume enough of the aposematic prey to significantly learn to avoid them (see Lee et al. 2010) and as our initial Page 23 of 39 
models show, accelerated avoidance learning about aposematic prey is required for them to survive and spread in scenarios where predators significantly outlive their prey $\left(\operatorname{Pred}_{\text {gen }}=5\right)$. A similar result pertains, although to a much less detrimental level, when we allow random, global predator movement across the metapopulation, between prey generations. This difference in effect between local and globally mobile predators may arise due to local predators exhausting their wariness of the aposematic form quite quickly due to constant encounter (especially in the first instance whereby we assume four habitats begin the model at aposeme fixation). The effect of global predator movement ensures that, in most cases, a completely naive predator moves into the habitat and hence its DC wariness has not been eroded by experience.

We suggest that when aposematism arises in an isolated sub-population(s), it is most likely to spread to surrounding habitats when a single predator's patch approximately matches the area inhabited by a sub-population and when predators generally remain in that habitat for the duration of their lifetime. Although this presents a limiting scenario, we show that aposematism can indeed spread if predators are themselves geographically mobile although these conditions are found to be less favourable.

When we allow total prey migration along with globally moving predators then the model outcome is similar to the random predator, single habitat models described by Lee et al. (2010) in that the learning rate required for fixation of the aposematic morph is significantly raised, affirming the importance of habitat and population structure on the evolution of aposematic displays.

\section{Predator Abundance}

When the number of predators across the metapopulation was reduced, thus allowing some subhabitats to remain predator free for a period of time, the probability of survival and spread of the Page 24 of 39 
aposematic morph was reduced. Although pilot studies showed that over long periods of evolutionary time, the unidirectional mutation towards the aposematic form and reproductive drift in the absence of predation could account for the fixation of the aposematic morph, our model shows that even with a significantly reduced number of predators in the modelled system, fixation is of the aposematic form was unlikely and required high levels of predator avoidance learning. This indicates that with free roaming predators, it is unlikely that a sub-population would escape predation long enough for drift to raise the abundance of the aposematic morph. Our model suggests that for drift to account for the fixation or at least increased abundance of aposematic prey, predation must be absent for sufficient periods of evolutionary time.

\section{Mallet \& Singer's Predictions}

Our models show a shifting balance and moving clines as predicted by (Mallet and Singer 1987), in the sense that sufficient localisation in frequency of aposematic signals within a habitat could cause the destabilisation of crypsis in neighbouring habitats, and the outward movement of aposematism/crypsis clines. Because we have modelled asexual reproduction, we are of course not intending to describe the specific complications of sex or allelic dominance. It should also be pointed out that the random component in genetic drift comes in our models through stochastic repopulation of the prey between generations. None the less, even with these limitations, it can be seen that Mallet \& Singer's general prediction, of localised evolution followed by shifting clines holds up well. The important insight from our models is, in our view, that although prey migration works to prevent the evolution of geographically widespread aposematism, localised clustering of aposematism across several habitats may effectively surmount the barrier posed by migration.

Page 25 of 39 


\section{Stable Dimorphism and the persistence of aposematic prey}

Our models show that where predator/prey lifespans are similar, and with moderate avoidance learning rates for aposematic prey $\left(\alpha_{\mathrm{a}}=0.04-0.17\right)$, we observe stable co-existence of cryptic and aposematic morphs over the duration of the model, even when suffering attack from predators with large variation in their DC tendency. This result could not be demonstrated in single habitat models (Lee et al. in press). Metapopulation structure and the inter-habitat movement of prey therefore appear to prevent extinction of the aposematic morph by outmigration and establishment in other sub-habitats where predators may be more wary of the novel immigrant. Examples of metapopulation dispersal acting to prevent complete extinction is well supported in the literature (Holyoak and Lawler 1996; Sabelis and Diekmann 1988) describing a 'hide and seek' phenomenon whereby prey migrate to a beneficial habitat with the effect that extinction is prevented. Although these studies describe asynchrony between predator and prey populations as the protecting mechanism preventing extinction, in our model 'havens' are created when a habitats contains a highly wary predator.

\section{Conclusions}

The models presented in this study provide insight into the effect that population structure may have had on the initial evolution and geographical spread of aposematism which previous studies have so far neglected. Aposematic warning displays clearly exist and must have spread throughout prey populations at some point in natural history. There are many examples of aposematic species which have been shown to conform to general metapopulation structure, from the red-spotted newt (Notophthalmus viridescens),(Shure et al. 1989) to the six-spot burnet moth (Zygaena filipendulae),(Menendez et al. 2002). Our model provides a missing insight into how such prey Page 26 of 39 
populations might have evolved conspicuous warning signals and how aposematism might have become established over time and geographic space. We re-iterate that initial localized increase in frequency, may have been crucial to the evolution of warning colouration within such species followed by low levels of out-migration.

\section{Acknowledgements}

TL was funded by a NERC PhD studentship; MPS was supported by a Leverhulme Trust Research Fellowship. We thank Graeme Ruxton \& Nicola Marples for advice.

Page 27 of 39 


\section{References}

Cott, H. B. 1940. Adaptive coloration in animals. London: Methuen.

Edmunds, M. 1974. Defence in Animals: A survey of anti-predator defences. Harlow, Essex:

Longman.

Endler, J. A. \& Rojas, B. 2009. The Spatial Pattern of Natural Selection When Selection Depends on Experience. American Naturalist, 173, E62-E78.

Gill, D. E. 1978. The Metapopulation Ecology of the Red-Spotted Newt, Notophthalmus viridescens (Rafinesque). Ecological Monographs, 48, 145-166.

Hanski, I. 1998. Metapopulation dynamics. Nature, 396, 41-49.

Hanski, I. 1999. Metapopulation ecology. Oxford: Oxford University Press.

Harvey, P. H., Bull, J. J., Pemberton, M. \& Paxton, R. J. 1982. The evolution of aposematic coloration in distasteful prey - a family model. American Naturalist, 119, 710-719.

Holyoak, M. \& Lawler, S. P. 1996. Persistence of an extinction-prone predator-prey interaction through metapopulation dynamics. Ecology, 77, 1867-1879.

Lee, T. J., Marples, N. M. \& Speed, M. P. in press. Can dietary conservatism explain the primary evolution of aposematism. Animal Behaviour.

Lee, T. J., Marples, N. M. \& Speed, M. P. 2010. Can dietary conservatism explain the primary evolution of aposematism? Animal Behaviour, 79, 63-74.

Leimar, O., Enquist, M. \& Sillén-Tullberg, B. 1986. Evolutionary stability of aposematic coloration and prey unprofitability - a theoretical-analysis. American Naturalist, 128, 469-490.

Levins, R. 1969. Some demographic and genetic consequences of environmental heterogeneity for biological control. . Bulletin of the Entomological Society of America 15, 237-240.

Mallet, J. \& Singer, M. C. 1987. Individual Selection, Kin Selection, and the Shifting Balance in the Evolution of Warning Colors - the Evidence from Butterflies. Biological Journal of the Linnean Society, 32, 337-350.

Marples, N. M., Kelly, D. J. \& Thomas, R. J. 2005. Perspective: The evolution of warning coloration is not paradoxical. Evolution, 59, 933-940.

Marples, N. M., Roper, T. J. \& Harper, D. G. C. 1998. Responses of wild birds to novel prey: evidence for dietry conservatism. Oikos, 83, 161-165.

Marsh, D. M. \& Trenham, P. C. 2001. Metapopulation dynamics and amphibian conservation. Conservation Biology, 15, 40-49.

Menendez, R., Gutierrez, D. \& Thomas, C. D. 2002. Migration and Allee effects in the six-spot burnet moth Zygaena filipendulae. Ecological Entomology, 27, 317-325.

Poulton, E. B. 1890. The Colours of Animals: their meaning and use especially considered in the case of insects. London: Kegan Paul, Trench, Trubner \& co. Ltd.

Przeczek, K., Mueller, C. \& Vamosi, S. M. 2008. The evolution of aposematism is accompanied by increased diversification. Integrative Zoology, 3, 149-156.

Puurtinen, M. \& Kaitala, V. 2006. Conditions for the spread of conspicuous warning signals: A numerical model with novel insights. Evolution, 60, 2246-2256.

Sabelis, M. W. \& Diekmann, O. 1988. Overall Population Stability Despite Local Extinction - the Stabilizing Influence of Prey Dispersal from Predator-Invaded Patches. Theoretical Population Biology, 34, 169-176.

Saporito, R. A., Zuercher, R., Roberts, M., Gerow, K. G. \& Donnelly, M. A. 2007. Experimental evidence for aposematism in the dendrobatid poison frog Oophaga pumilio. Copeia, 1006-1011.

Servedio, M. R. 2000. The effects of predator learning, forgetting, and recognition errors on the evolution of warning coloration. Evolution, 54, 751-763.

Page 28 of 39 
Sherratt, T. N. 2006. Spatial mosaic formation through frequency-dependent selection in Müllerian mimicry complexes. Journal of Theoretical Biology, 240, 165-174.

Shure, D. J., Wilson, L. A. \& Hochwender, C. 1989. Predation on Aposematic Efts of Notophthalmus-Viridescens. Journal of Herpetology, 23, 437-439.

Smith, J. N. M. 1974. Food Searching Behavior of 2 European Thrushes - Adaptiveness of Search Patterns. Behaviour, 49, 1-61.

Snow, D. W. 1966. Migration and Dispersal of British Blackbirds. Bird Study, 13, 237-\&.

Speed, M. P. 2001. Can receiver psychology explain the evolution of aposematism? Animal Behaviour, 61, 205-216.

Speed, M. P. \& Ruxton, G. D. 2007. How bright and how nasty: Explaining diversity in warning signal strength. Evolution, 61, 623-635.

Speed, M. P. \& Ruxton, G. D. 2005. Aposematism: what should our starting point be? Proceedings of the Royal Society B-Biological Sciences, 272, 431-438.

Thomas, R. J., Bartlett, L. A., Marples, N. M., Kelly, D. J. \& Cuthill, I. C. 2004. Prey selection by wild birds can allow novel and conspicuous colour morphs to spread in prey populations. Oikos, 106, 285-294.

Thomas, R. J., Marples, N. M., Cuthill, I. C., Takahashi, M. \& Gibson, E. A. 2003. Dietary conservatism may facilitate the initial evolution of aposematism. Oikos, 101, 458-466.

Yachi, S. \& Higashi, M. 1998. The evolution of warning signals. Nature, 394, 882-884.

Tables

Page 29 of 39 
Table 1 - Standard Parameters Used for All Models Unless Otherwise Stated

\begin{tabular}{|c|c|c|}
\hline Parameter Name & Parameter Description & Fixed Values \\
\hline $\mathrm{T}$ & $\begin{array}{l}\text { Arbitrary time limit for each } \\
\text { generation }\end{array}$ & 100 \\
\hline $\mathrm{N}$ & Total number of prey & 400 \\
\hline generations & $\begin{array}{l}\text { Number of Generations } \\
\text { Simulated }\end{array}$ & 2000 \\
\hline $\mathrm{N}_{\mathrm{a}}$ & Number of aposematic prey & $\begin{array}{l}10 \text { spawned across the } \\
\text { entire metapopulation } \\
\text { each generation based on } \\
\text { mutationrate (see below) }\end{array}$ \\
\hline $\mathrm{N}_{\mathrm{c}}$ & Number of cryptic prey & 399 \\
\hline $\mathrm{c}_{\mathrm{a}}$ & $\begin{array}{l}\text { Conspicuousness of aposematic } \\
\text { prey (also representative of the } \\
\text { detection probability) }\end{array}$ & 0.02 \\
\hline $\mathrm{c}_{\mathrm{c}}$ & $\begin{array}{l}\text { Conspicuousness of cryptic prey } \\
\text { (also representative of the } \\
\text { detection probability) }\end{array}$ & 0.01 \\
\hline$\alpha_{a}$ & $\begin{array}{l}\text { Predator avoidance learning rate } \\
\text { for aposematic prey }\end{array}$ & $\begin{array}{l}\text { Variable (see individual } \\
\text { model description) }\end{array}$ \\
\hline$\alpha_{c}$ & $\begin{array}{l}\text { Predator avoidance learning rate } \\
\text { for cryptic prey }\end{array}$ & 0.04 \\
\hline $\mathrm{DC}_{\text {num }}$ & $\begin{array}{l}\text { Number of prey rejected due to } \\
\text { fixed Dietary Conservatism } \\
\text { memory }\end{array}$ & $\begin{array}{l}\text { Variable (taken from } \\
\text { empirical data in } \\
\text { Marples, 1998. See Table } \\
\text { 2) }\end{array}$ \\
\hline mig gen $_{\text {gen }}$ & $\begin{array}{l}\text { Prey generation in which we } \\
\text { allow prey migration to begin }\end{array}$ & 2 \\
\hline mutationrate & $\begin{array}{l}\text { Rate of incidence of aposematic } \\
\text { mutants }\end{array}$ & $10^{-5}$ \\
\hline $\mathrm{N}_{\text {mig }}$ & $\begin{array}{l}\text { Number of prey migrating to } \\
\text { each surrounding habitat }\end{array}$ & $\begin{array}{l}\text { Variable (see individual } \\
\text { model description) }\end{array}$ \\
\hline pred $_{\text {gen }}$ & $\begin{array}{l}\text { Prey generation intervals at } \\
\text { which the predators are replaced }\end{array}$ & $\begin{array}{l}\text { Variable (see individual } \\
\text { model description) }\end{array}$ \\
\hline
\end{tabular}

Page 30 of 39 
Table 2 - Pool of Predators and Associated Fixed D.C Values Used in Subsequent Models (values from Marples et al. 1998)

\begin{tabular}{|l|l|l|l|l|l|l|l|l|l|l|l|l|l|}
\hline Predator Number & 1 & 2 & 3 & 4 & 5 & 6 & 7 & 8 & 9 & 10 & 11 & 12 & 13 \\
\hline Number Of Novel Prey Avoided & 125 & 49 & 114 & 3 & 15 & 10 & 3 & 10 & 14 & 6 & 3 & 24 & 6 \\
\hline
\end{tabular}

Page 31 of 39 
Table 3 - Comparison between the results of the single habitat models of Lee et al and the equivalent metapopulation implementation. In all simulations $\alpha_{c}=0.04$.

\begin{tabular}{|c|c|c|}
\hline $\begin{array}{l}\text { Modelled Scenario } \\
\text { \& Parameters }\end{array}$ & $\begin{array}{l}\text { Single Habitat Model } \\
\text { (Lee et al. in press) }\end{array}$ & Metapopulation Model \\
\hline $\begin{array}{l}\text { No Predator wariness (Null } \\
\text { model) variable learning rate for } \\
\text { aposematic prey }\left(\alpha_{\mathrm{a}}=0.04-0.99 \text {, }\right. \\
\left.\operatorname{pred}_{\text {gen }}=1\right)\end{array}$ & $\begin{array}{l}\text { No increase in abundance of } \\
\text { aposematic prey }\end{array}$ & $\begin{array}{l}\text { No increase in abundance of } \\
\text { aposematic prey }\end{array}$ \\
\hline $\begin{array}{l}\text { Random Predator wariness with } \\
\text { equal predator-prey lifespans } \\
\left(\alpha_{\mathrm{a}}=0.04-0.99, \text { pred }_{\text {gen }}=1\right)\end{array}$ & $\begin{array}{l}\text { Fixation of the aposematic } \\
\text { morph occurred where } \\
\left(\alpha_{\mathrm{a}}=>0.08\right) \text {. No dynamic } \\
\text { equilibrium in any trials. }\end{array}$ & $\begin{array}{l}\text { Dynamic equilibrium where } \\
\left(\alpha_{\mathrm{a}}=0.04-0.17\right) . \text { Fixation of the } \\
\text { aposematic morph where } \\
\left(\alpha_{\mathrm{a}}>=0.18\right) .\end{array}$ \\
\hline 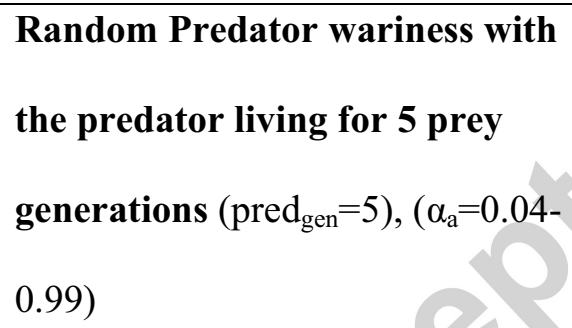 & $\begin{array}{l}\text { Fixation of the aposematic } \\
\text { morph where }\left(\alpha_{\mathrm{a}}=>0.35\right) \text {. } \\
\text { No dynamic equilibrium in } \\
\text { any trials. }\end{array}$ & $\begin{array}{l}\text { No increase in abundance of } \\
\text { aposematic prey. }\end{array}$ \\
\hline
\end{tabular}

Page 32 of 39 


\section{Figure legends}

Figure 1 - Stable coexistence of competing prey morphs demonstrated over 2000 prey generations (generations $=2000$, $\mathrm{T}=100, \mathrm{c}_{\mathrm{a}}=0.02, \mathrm{c}_{\mathrm{c}}=0.01, \alpha_{\mathrm{c}}=0.04, \alpha_{\mathrm{a}}=0.17, \operatorname{pred}_{\mathrm{gen}}=1, \operatorname{mig}_{\mathrm{gen}}=2$, mutationrate $=10^{-5}, \mathrm{DC}_{\text {num }}=$ random $($ Table 2$)$, $\mathrm{N}_{\text {mig }}=10$ ). The solid line represents the number of aposematic prey and the dotted line represents the number of cryptic prey.

Figure 2 -Metapopulation model plot showing the temporal spread of aposematism from a single zone within the metapopulation $\left(\right.$ generations $=2000, \mathrm{~T}=100, \mathrm{c}_{\mathrm{a}}=0.02, \mathrm{c}_{\mathrm{c}}=0.01, \alpha_{\mathrm{c}}=0.04, \alpha_{\mathrm{a}}=0.18$, pred $_{\mathrm{gen}}=1, \operatorname{mig}_{\mathrm{gen}}=2$, mutationrate $=10^{-5}, \mathrm{DC}_{\text {num }}=$ random $\left(\right.$ Table2), $\left.\mathrm{N}_{\text {mig }}=10\right)$.

Figure 3-Metapopulation model with 4 grouped source habitats at aposematic fixation $-($ generations $=2000, T=100$, $\mathrm{c}_{\mathrm{a}}=0.02, \mathrm{c}_{\mathrm{c}}=0.01, \alpha_{\mathrm{c}}=0.04, \alpha_{\mathrm{a}}=0.55, \operatorname{pred}_{\mathrm{gen}}=5, \operatorname{mig}_{\mathrm{gen}}=1$, mutationrate $=10^{-5}, \mathrm{~N}_{\mathrm{mig}}=10, \mathrm{DC}_{\text {num }}=$ random $($ Table 2$\left.)\right)$. The solid line represents the number of aposematic prey and the dotted line represents the number of cryptic prey.

Figure 4-Metapopulation model plot showing the temporal spread of aposematism from the centre 4 clustered subhabitats $\left(\right.$ generations $=2000, \mathrm{~T}=100, \mathrm{c}_{\mathrm{a}}=0.02, \mathrm{c}_{\mathrm{c}}=0.01, \alpha_{\mathrm{c}}=0.04, \alpha_{\mathrm{a}}=0.38$, pred $_{\mathrm{gen}}=5$, mig $_{\text {gen }}=1$, mutationrate $=10^{-5}$, $\mathrm{N}_{\mathrm{mig}}=10, \mathrm{DC}_{\text {num }}=$ random $($ Table2)).

Figure 5 - Average net gain in abundance over 1 generation due to selection (solid line) vs net loss to migration (dotted line) for varied starting abundances of aposematic prey (Nmig=2, generations $=1, \mathrm{~N}_{c}=400-\mathrm{N}_{\mathrm{a}}, N_{a=20}-380, T=100$, $c_{a}=0.02, c_{c}=0.01, \alpha_{c}=0.04, \alpha_{a}=0.38, \operatorname{pred}_{\text {gen }}=5, D C_{\text {num }}=\operatorname{random}($ Ta ble2) $)$.

\section{Figure 6}

(a) - The effect of back-migration on a single source habitat at aposeme abundance (Nmig=5, generations $=100, T=100$, $c_{a}=0.02, c_{c}=0.01, \alpha_{c}=0.04, \alpha_{a}=0.38, \operatorname{pred}_{\text {gen }}=5, D C_{\text {num }}=$ random (Table2)). The dotted line represents the overall Page 33 of 39 
abundance of aposematic prey within the habitat, the solid line represents the number of aposematic prey lost to outmigration and the dashed line represents the number of aposematic prey gained by in-migration. Note as aposematism becomes established in the sink habitats, we observe increasing in-migration until eventually in and out migration levels equalize.

(b) - Change in abundance of aposematic prey in a source habitat over 100 generations. The solid line represents a single solitary source habitat, the dashed line represents a border habitat in a 3x3 source habitat clump and finally the dotted line represents the centre habitat in the $3 \times 3$ cluster with all source habitats lying at the centre of a $6 \times 6$ test metapopulation. (generations $=100, \mathrm{~T}=100, \mathrm{c}_{\mathrm{a}}=0.02, \mathrm{c}_{\mathrm{c}}=0.01, \alpha_{\mathrm{c}}=0.04, \alpha_{\mathrm{a}}=0.38$, pred $_{\text {gen }}=5, \mathrm{DC}_{\text {num }}=\mathrm{random}$ (Table2),Nmig=5 ).

Page 34 of 39 


\section{Appendix}

\section{Null Model 1 - No D.C. With Equal Avoidance Learning Rates}

In the first presentation of the model we ran a simple null test to determine if the aposematic prey morph could invade from rare where avoidance learning rates were equal for both prey types and where the predators show no dietary conservatism. The model adopts the standard parameters (see table 1) other than where explicitly stated.

Here, the predators showed no D.C tendency $\left(D C_{\text {num }}=0\right.$ for all predators). Predator avoidance learning rate for both prey types was set to be equal ( $\alpha_{a}=0.04$ and $\left.\alpha_{a}=0.04\right)$. We allowed 10 prey to migrate to each of the surrounding habitats each prey generation $\left(N_{\text {mig }}=10\right)$ giving 80 total migratory prey. Migration began in the second generation of the model $($ miggen $=2)$. In this model we assumed that the predators and prey live for equal lengths of time $\left(\right.$ pred $\left._{g e n}=1\right)$.

Results

At no point in the simulation did the aposematic morph increase in abundance showing that without predators showing dietary conservatism and the benefits of accelerated avoidance learning, a more conspicuous mutant in a cryptic prey population rapidly and repeatedly becomes extinct.

\section{Null Model 2 - No D.C. With Bias Avoidance Learning Rates}

Page 35 of 39 
The model was re-tested with the same parameters as in null model 1, however we now increased the avoidance learning rate for aposematic prey to $\left(\alpha_{a}=0.99\right)$ to determine whether fixation could occur if the predator learned to avoid the aposematic morph more quickly than its cryptic conspecific due to the combined effect of the warning signal and its toxicity.

As predicted by the previous single habitat models of Lee et al, at no point in the simulation did the aposematic morph increase in abundance. Increased avoidance learning alone provides insufficient protection for the novel aposematic prey to allow any increase in abundance.

\section{D.C. Model 1 - Dietary Conservatism with Equal Avoidance Learning}

Next, we introduce predator dietary conservatism to determine whether initial avoidance of the aposematic morph can cause any increase in abundance within the cryptic prey population. Each predator now assumes a DC level drawn randomly from the pool of DC values (Table 2) for the duration of its lifetime. We use the same parameter set as null model 1 whereby we assume equal learning rates $\left(\alpha_{a}=0.04\right.$ and $\left.\alpha_{c}=0.04\right)$ and equal predator-prey life spans ( pred $\left._{g e n}=1\right)$.

Results

Where predators show dietary conservatism and with equal avoidance learning rates for both cryptic and aposematic prey we now yield an increase in abundance of the aposematic morph (Figure A2). The aposematic prey reach an observed fixed abundance of approximately 50,000 individuals and sustained that abundance over the 2000 generation duration of the model in a state of dynamic equilibrium (correlation coefficient $r=0.164)$.

Page 36 of 39 


\section{D.C. model 2 - Dietary Conservatism with Bias Avoidance Learning}

Adopting the same parameters as D.C. model 1, we then tested increasing levels of avoidance learning rates for aposematic prey $\left(\alpha_{a}\right)$ to determine whether the state of dynamic equilibrium between competing morphs could be replicated with biased avoidance learning and to determine if a critical avoidance learning rate for aposematic prey existed which would allow fixation to occur.

Results

For values of avoidance learning rate for aposematic prey $\left(\alpha_{a}=0.04-0.17\right)$ we did not yield fixation of the aposematic morph but instead we again observe dynamic equilibrium between the competing prey morphs. Increasing $\alpha_{a}$ between these limits had the effect of increasing the abundance of aposematic prey at which dynamic equilibrium occurred (see Figure 1 in main text). We observe that the aposematic morph reaches dynamic equilibrium at an increased abundance of approximately 80,000 individuals compared to 50,000 for equal avoidance learning rates (Figure A1).Increasing the avoidance learning rate for aposematic prey $\left(\alpha_{\mathrm{a}}>=0.18\right)$ yielded fixation of the aposematic morph ( Figure A3).

\section{Model 3 - Increased Predator Lifespan}

In previous simulations we have shown that in the metapopulation habitat as described above with the predator life span set to be equal to that of the prey we observe dynamic equilibrium $\left(\alpha_{a}<0.18\right)$ and fixation of the aposematic morph $\left(\alpha_{a}>=0.18\right)$. Next we consider a model whereby predators 
now live for 5 prey generations $\left(\operatorname{pred}_{\text {gen }}=5\right)$ in order to determine whether dynamic equilibrium or fixation can occur under such conditions. We assume the same parameters as D.C. Model 1 and tested a range of values of avoidance learning rate for aposematic prey $\left(\alpha_{a}=0.04-0.99\right)$.

Results

In all trials, the aposematic morph did not increase in abundance at any point during the simulation indicating that when aposematic individuals arose by mutation, they rapidly became extinct. Lee et al (In press) showed that under the same conditions in a single habitat model, fixation of the aposematic morph could be demonstrated where the avoidance learning rate for aposematic prey was just ( $\alpha_{a}$ $=0.35$ ). Our models show therefore, that the inter-habitat movement of prey at the levels tested $\left(N_{m i g}=10\right)$ had a detrimental effect on the viability of the aposematic morph.

Page 38 of 39 


\section{Figure legends for Appendix}

Figure A1 - How rejection probability varies with number of encounters for various values of avoidance learning rate $(\alpha)$

Figure A2 -Dynamic equilibrium between the aposematic and cryptic morphs (generations $=2000, T=100, c_{a}=0.02$, $\mathrm{c}_{\mathrm{c}}=0.01, \alpha_{\mathrm{c}}=0.04, \alpha_{\mathrm{a}}=0.04, \operatorname{pred}_{\mathrm{gen}}=1, \operatorname{mig}_{\mathrm{gen}}=2$, mutationrate $=10^{-5}, \mathrm{DC}_{\text {num }}=$ random $\left.(\mathrm{Table} 2), \mathrm{N}_{\text {mig }}=10\right)$. The solid line represents the number of aposematic prey and the dotted line represents the number of cryptic prey.

Figure A3-Fixation of the aposematic morph (generations $=2000, \mathrm{~T}=100, \mathrm{c}_{\mathrm{a}}=0.02, \mathrm{c}_{\mathrm{c}}=0.01, \alpha_{\mathrm{c}}=0.04, \alpha_{\mathrm{a}}=0.18$, $\operatorname{pred}_{\text {gen }}=1, \operatorname{mig}_{\text {gen }}=2$, mutationrate $=10^{-5}, \mathrm{DC}_{\text {num }}=$ random $\left(\right.$ Table2), $\left.\mathrm{N}_{\text {mig }}=10\right)$. The solid line represents the number of aposematic prey and the dotted line represents the number of cryptic prey.

Page 39 of 39 


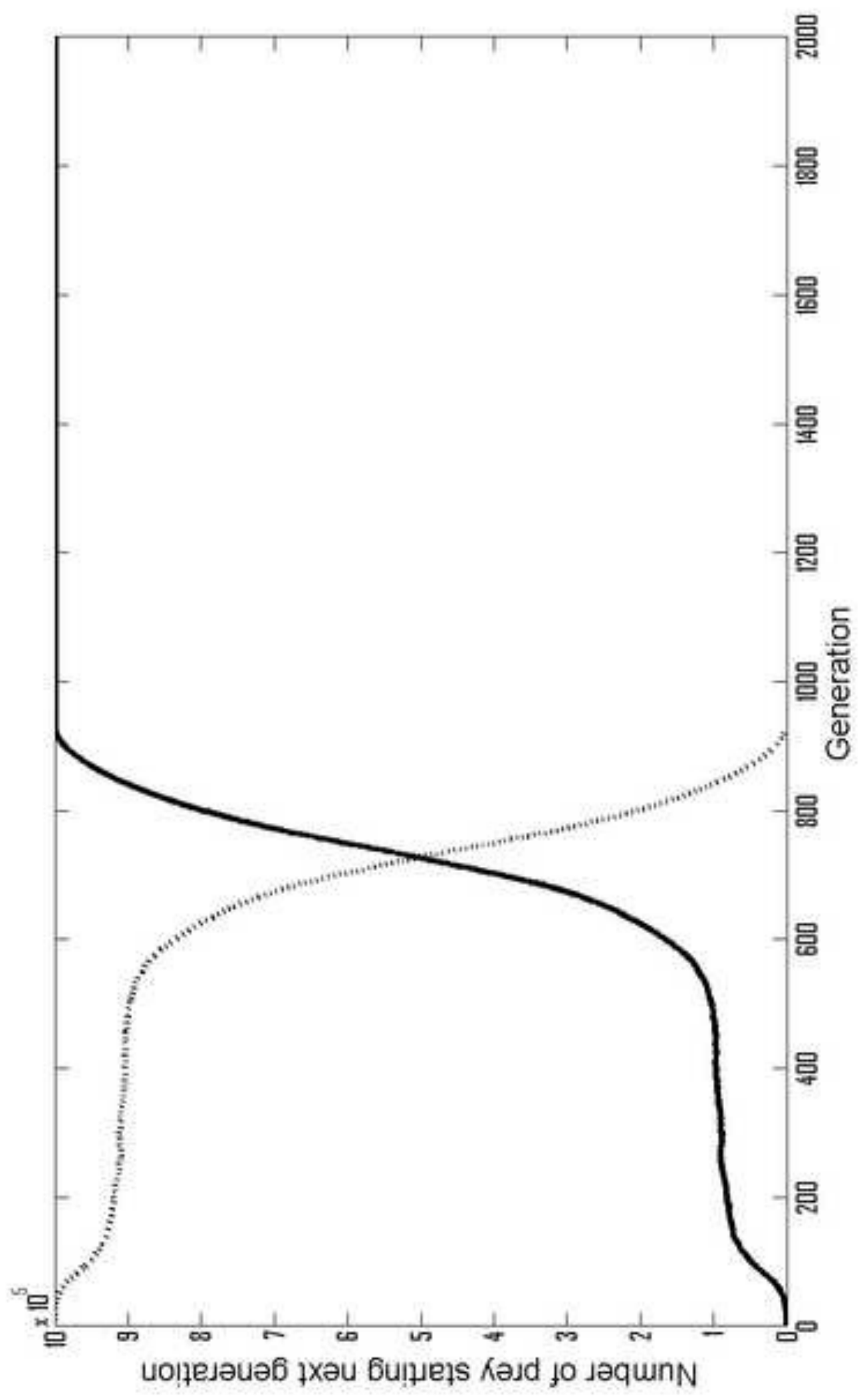




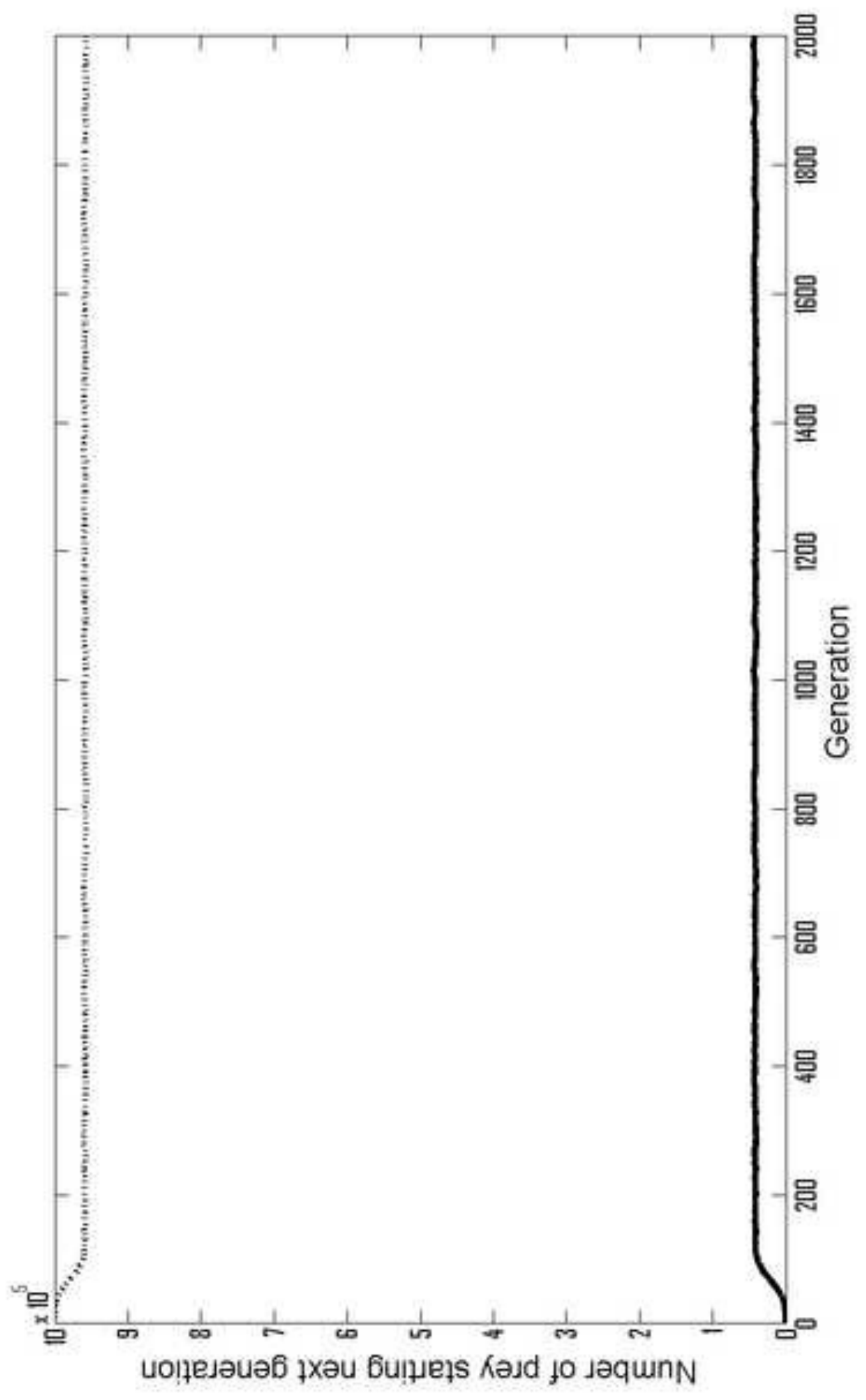




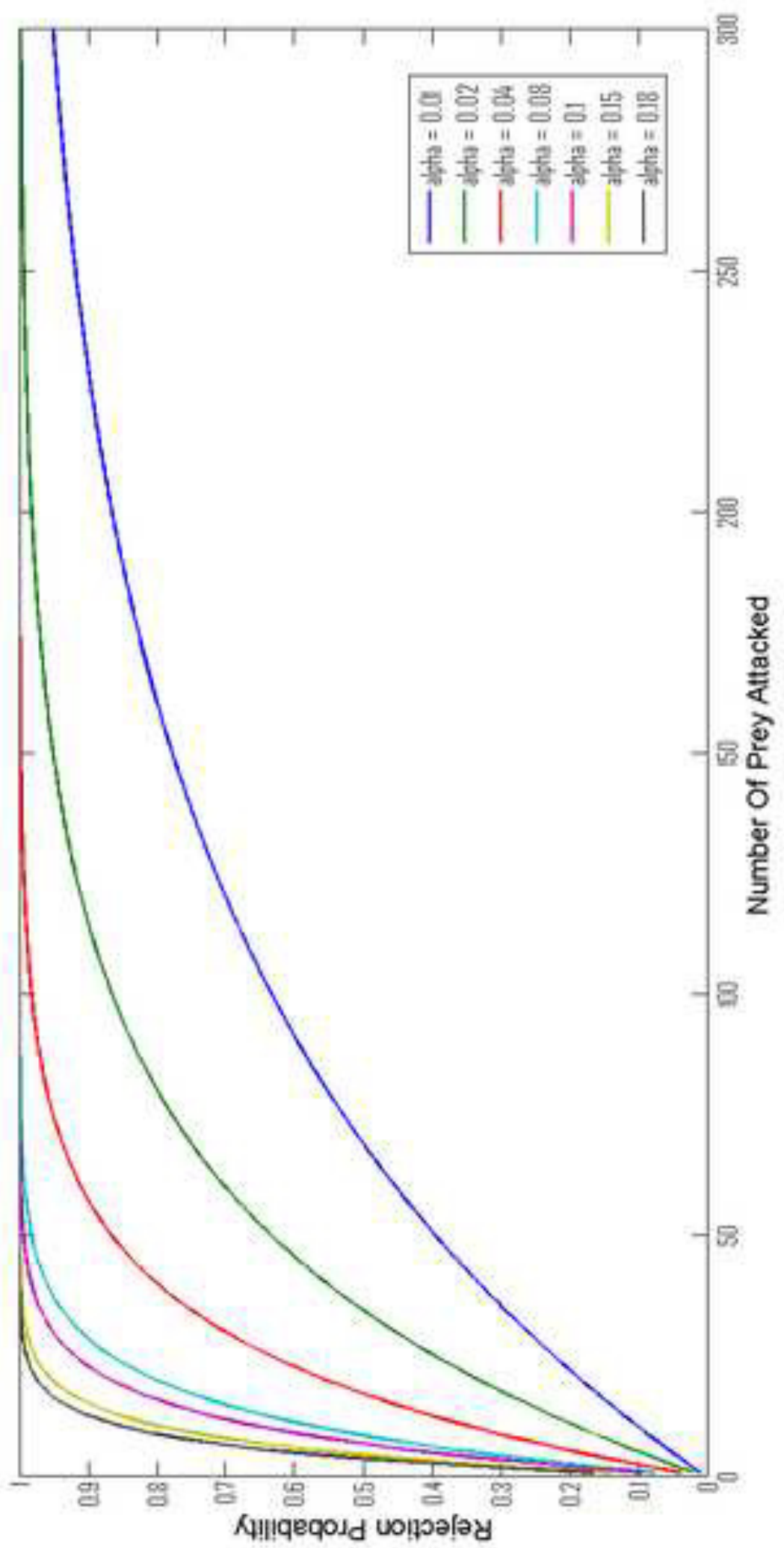




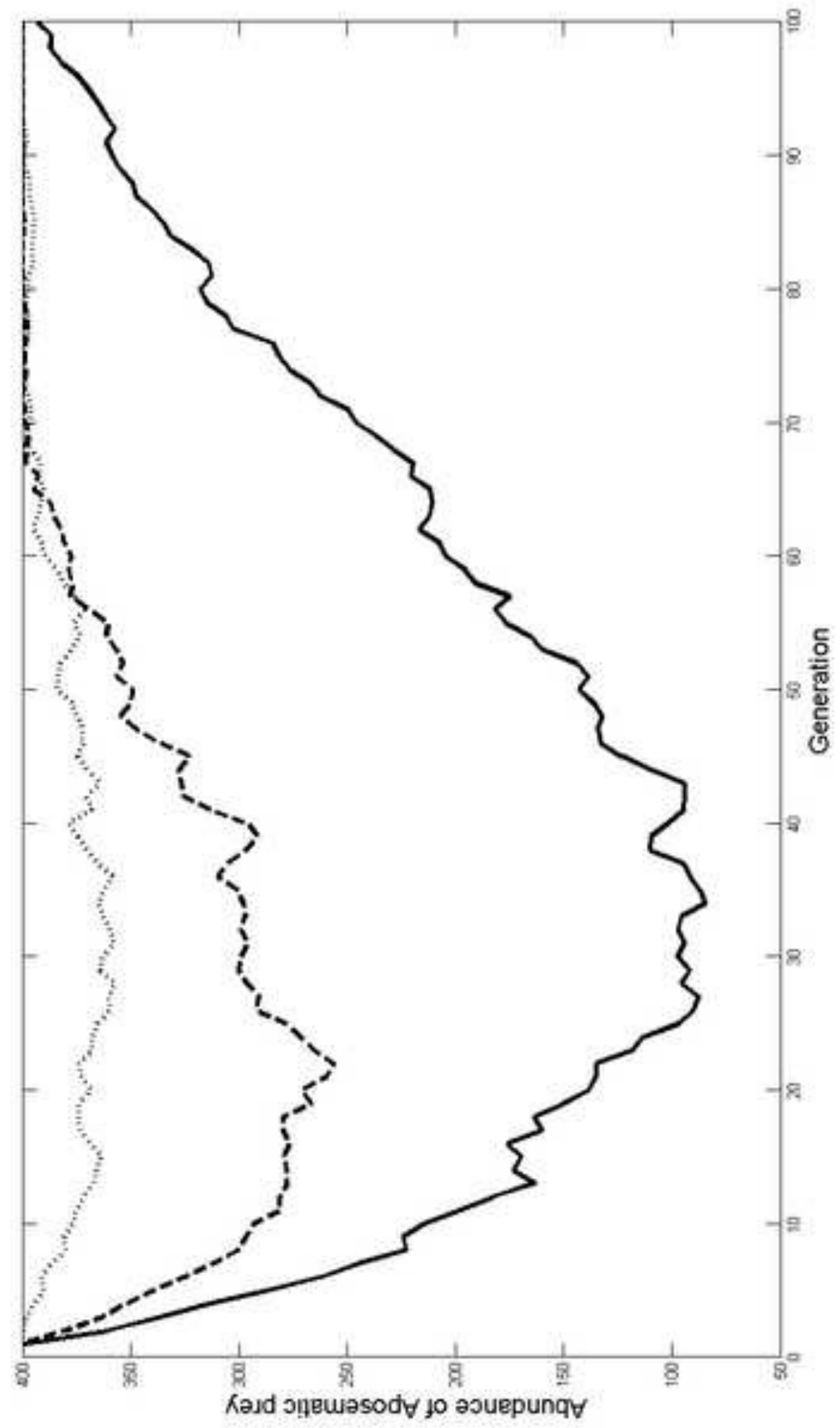




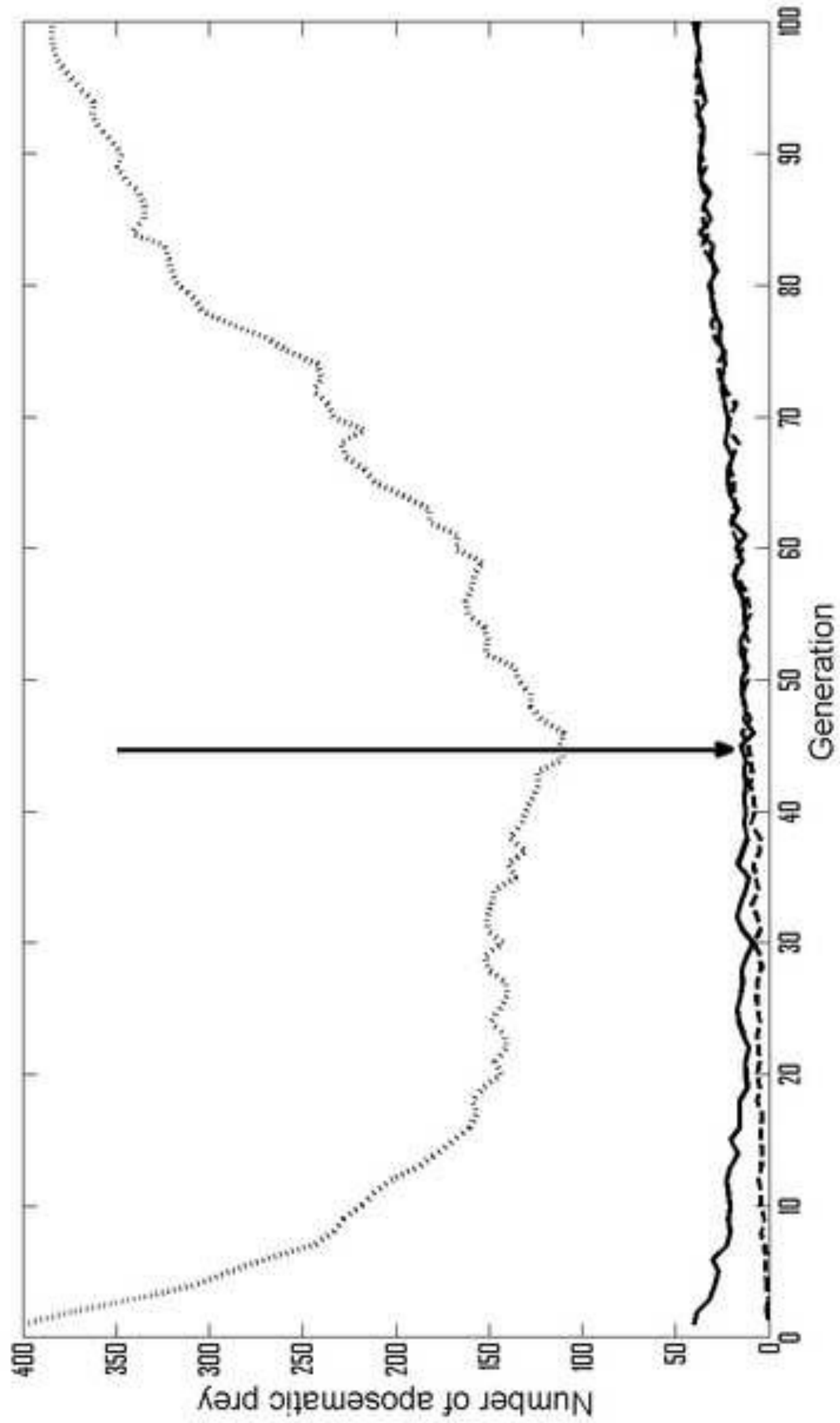




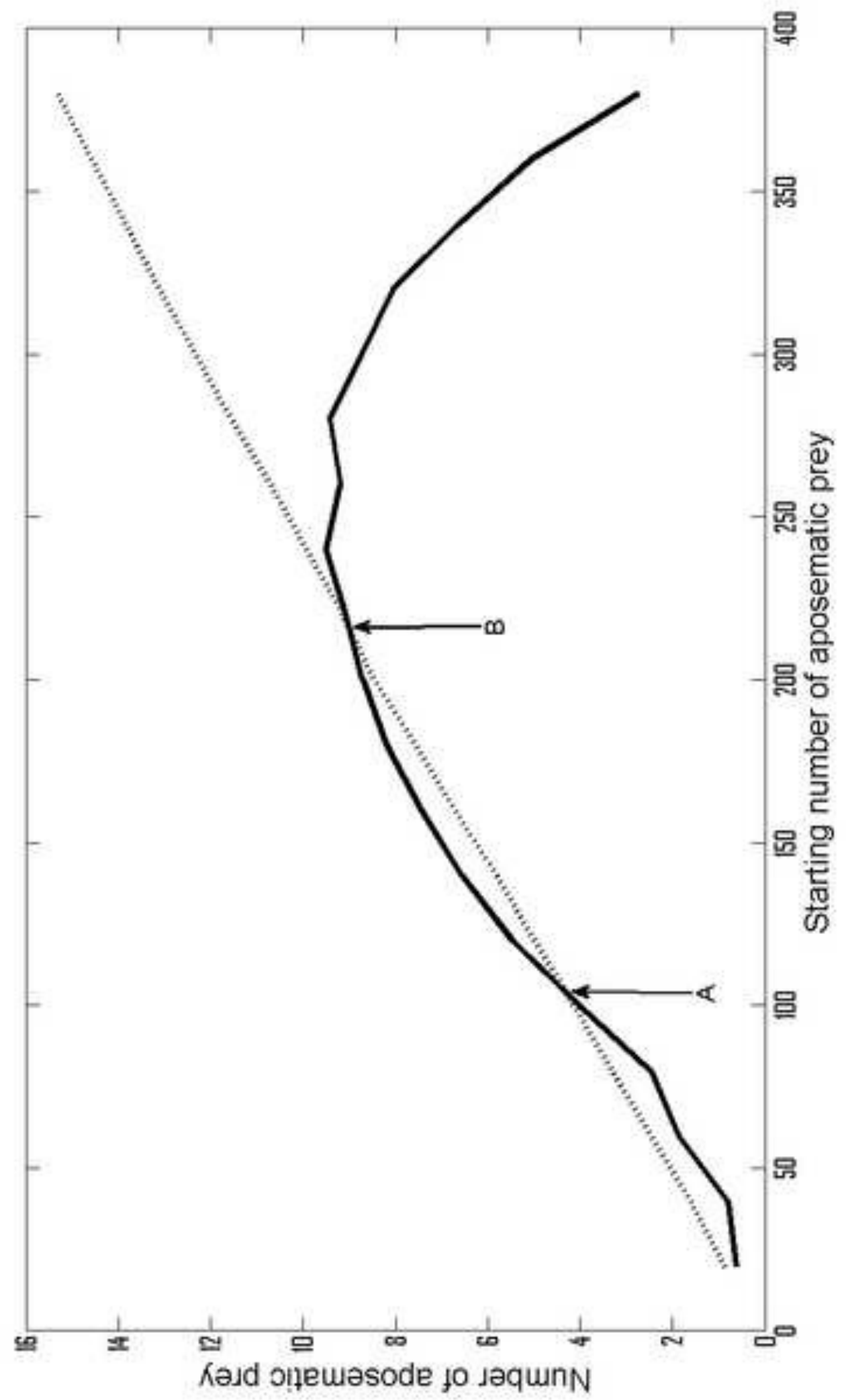




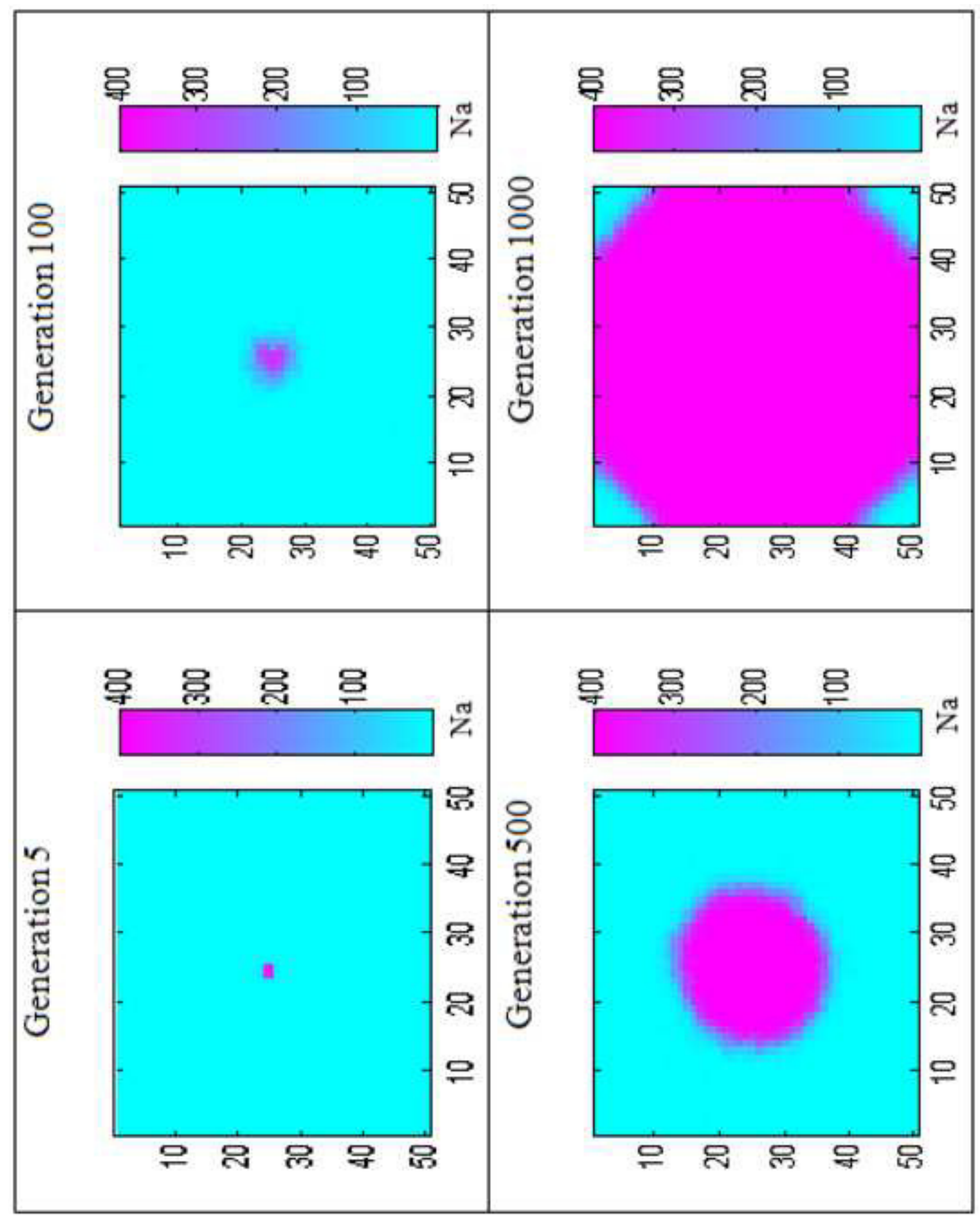




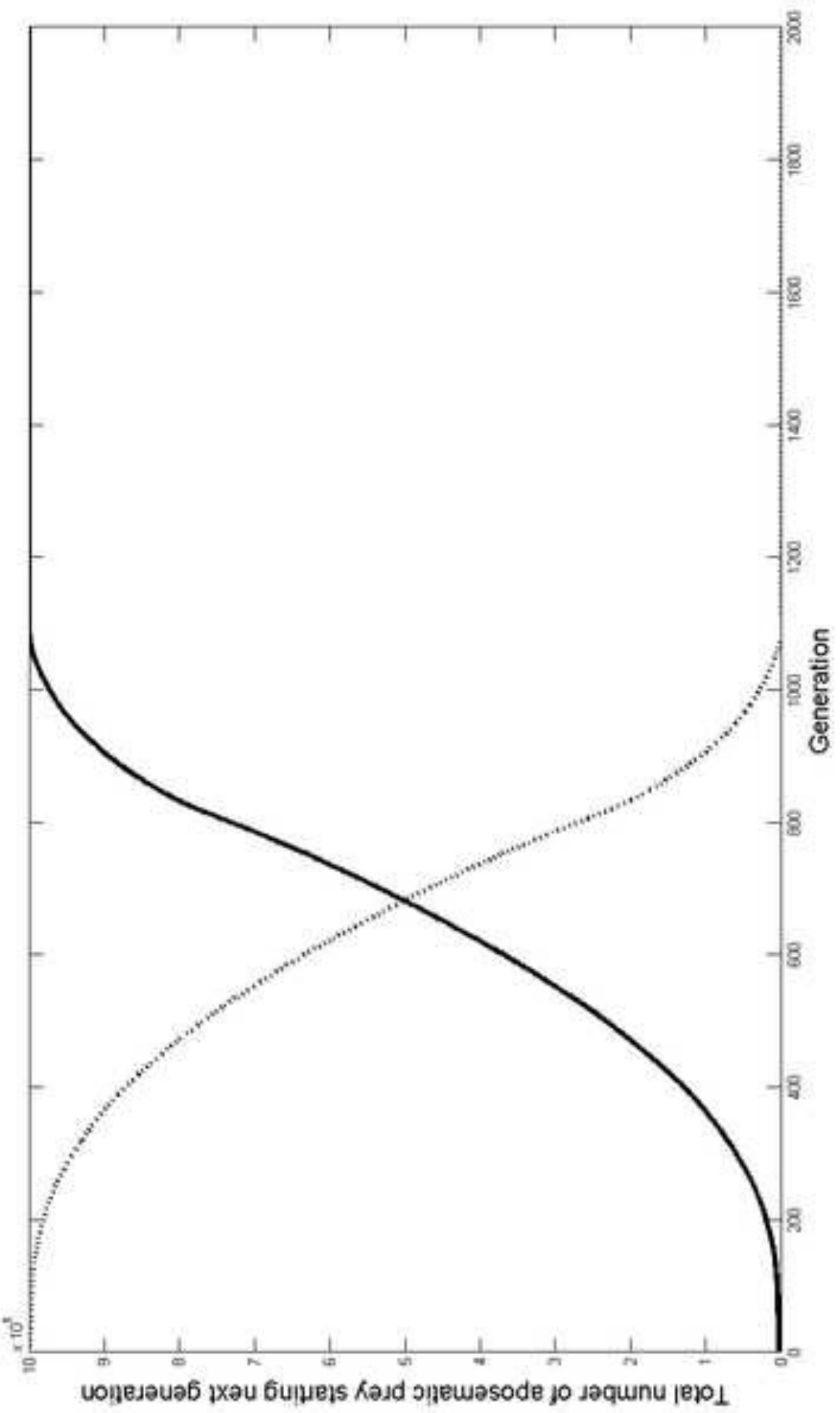




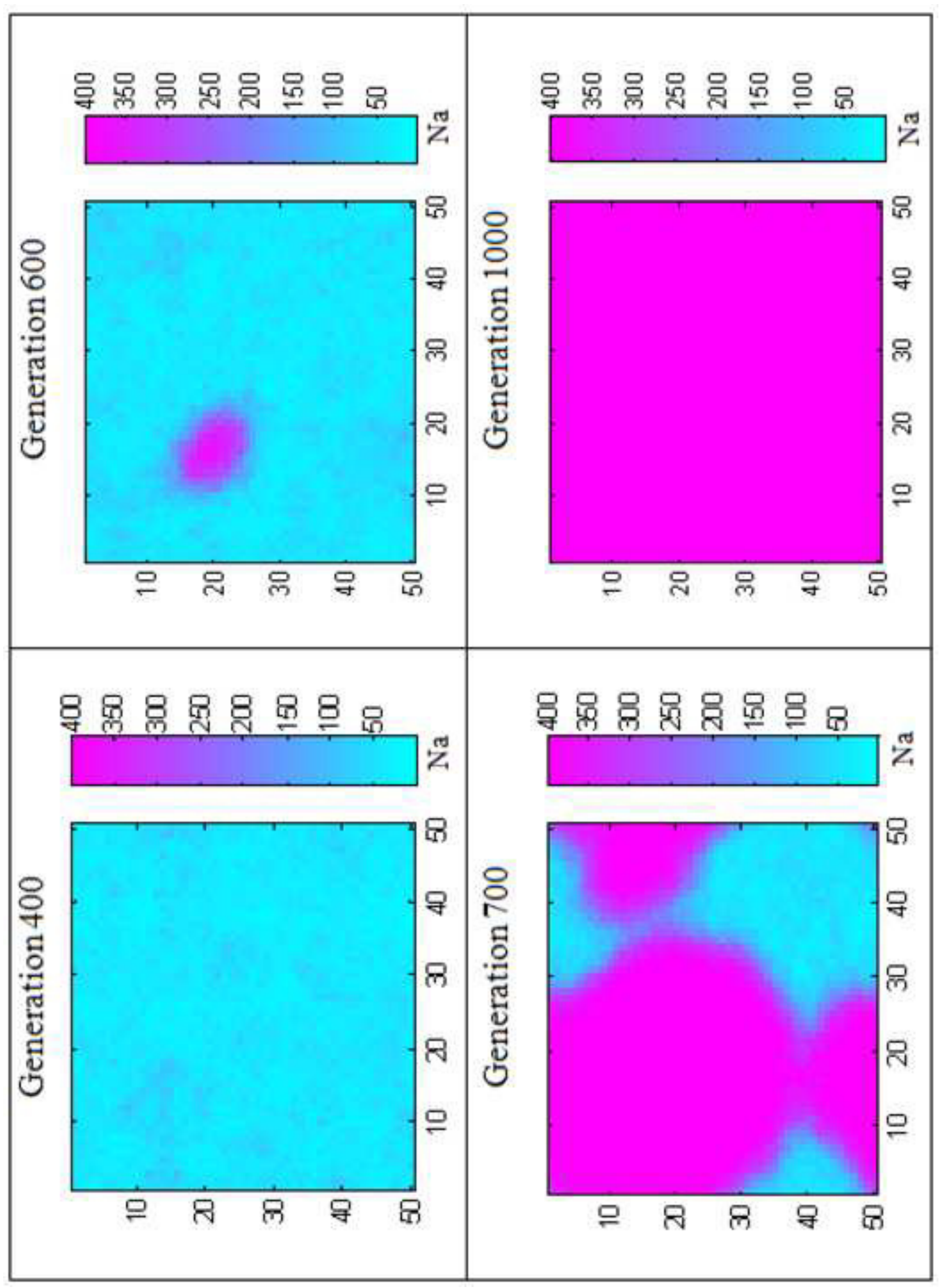




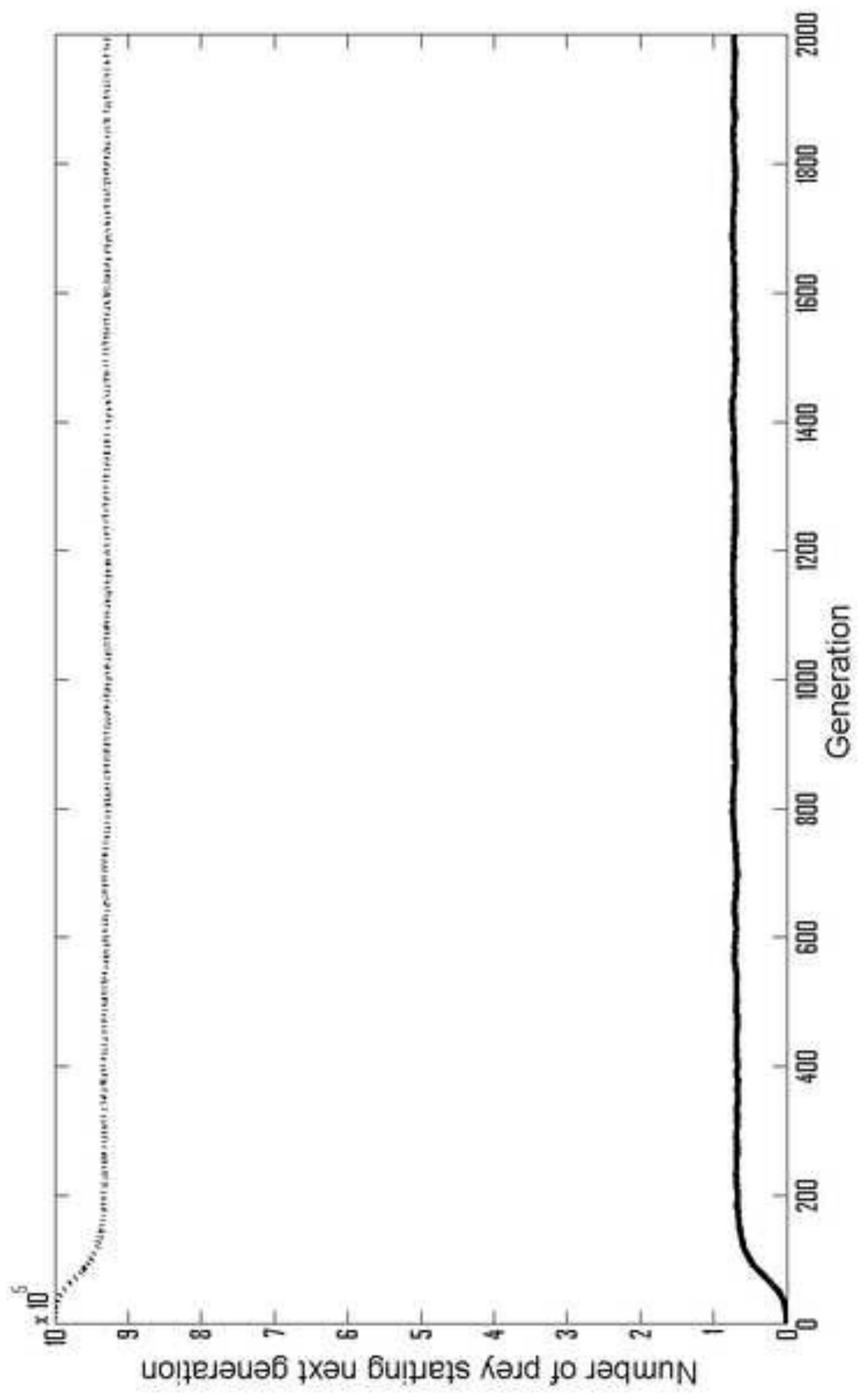

